\title{
Bioinspired reorientation strategies for application in micro/nanorobotic control
}

\author{
Ali Ghanbari ${ }^{1,2}$ (D) \\ Received: 28 October 2019 / Revised: 24 February 2020 / Accepted: 3 March 2020 / Published online: 8 April 2020 \\ (C) The Author(s) 2020
}

\begin{abstract}
Engineers have recently been inspired by swimming methodologies of microorganisms in creating micro-/nanorobots for biomedical applications. Future medicine may be revolutionized by the application of these small machines in diagnosing, monitoring, and treating diseases. Studies over the past decade have often concentrated on propulsion generation. However, there are many other challenges to address before the practical use of robots at the micro-/nanoscale. The control and reorientation ability of such robots remain as some of these challenges. This paper reviews the strategies of swimming microorganisms for reorientation, including tumbling, reverse and flick, direction control of helical-path swimmers, by speed modulation, using complex flagella, and the help of mastigonemes. Then, inspired by direction change in microorganisms, methods for orientation control for microrobots and possible directions for future studies are discussed. Further, the effects of solid boundaries on the swimming trajectories of microorganisms and microrobots are examined. In addition to propulsion systems for artificial microswimmers, swimming microorganisms are promising sources of control methodologies at the micro-/nanoscale.
\end{abstract}

Keywords bioinspired micro-/nanorobots $\cdot$ microrobot reorientation $\cdot$ microrobotic control $\cdot$ low Reynolds number

\section{Introduction}

Swimming microorganisms are ubiquitous in aquatic environments and larger bodies. Bacteria in our guts and mouths [1], protozoa in streams [2], archaea in marshlands [3], and algae in the ocean [4] are examples of these microscopic creatures. These organisms have inspired engineers in developing micro-/nanorobots for swimming in fluids. Bio-inspired artificial microswimmers, mimicking their natural counterparts, have the potential to revolutionize medical procedures. For this purpose, they not only need to propel themselves but also need to maneuver in applicable environments, such as in human body fluids.

The small size of microorganisms is captured by the Reynolds (Re) number in fluid mechanics, which indicates the importance of inertial forces versus viscous forces. For a swimming organism, the Re number depends on the organism's size and velocity, and on the viscosity of the fluid in

Ali Ghanbari

ghanbari@tafreshu.ac.ir

1 Mechanical Engineering Department, Tafresh University, Tafresh, Iran which it swims. Large and fast organisms, such as fish, have intermediate and high Re numbers. They swim using inertiabased methods such as body and caudal fin movement or median and paired fin propulsion $[5,6]$. However, swimming microorganisms have a very low Re number because of their small size and low speed [7].

Thus, different physics governs microscale versus macroscale swimming. In a low Re number environment, inertia is negligible when compared with drag, motion is time-reversible, and fin flapping generates no propulsion, as described by Purcell's scallop theorem [8]. Consequently, microorganisms use other methodologies to break the time reversibility in creeping flow to generate thrust [9-11]. Many microorganisms have hair-like appendages, called flagella and cilia, protruding from their bodies as organelles for swimming. In eukaryotes, a wave is formed and travels along the organism's flagella, and its interaction with the fluid generates propulsion, as in the case of the sea-urchin, human and insect spermatozoa [12-15]. Prokaryotes such as E. coli have helical flagella driven by a molecular motor embedded in the cell [16]. Other organisms use rows of cilia to paddle against the fluid. Asymmetric cilia motion during power and recovery strokes breaks the time reversibility in low $\mathrm{Re}$ number flow [17]. Some organisms combine and exploit 
two locomotion strategies simultaneously [18], or invoke more complex propulsion methodologies [19]. There are many reports on the motion of swimming microorganisms. Taylor pioneered the field by answering the question of how a body propels itself when inertia loses its efficiency compared to viscous forces [20].

Advances in microscopy and technical instruments, such as the invention of electron microscopy in 1931, augmented observations and investigations of microorganisms $[21,22]$. Progresses in the study of hydrodynamics at low Re numbers over the years are described in many reviews, including those by Happel and Brenner [23], Lighthill [24, 25], Brennen and Winet [17], Blum and Hines [26], Childress [27], and Kim and Karrila [28]. A review by Lauga and Powers covered recent advances in the hydrodynamics of swimming microorganisms [29]. These studies mostly discuss locomotion and the related physics in low Re number flow. This review aims to investigate the methods that swimming microorganisms use to change and control their direction, a subject on which less attention has been focused.

Several microrobots have been designed and developed with inspiration from microorganisms. The swimming methodologies of these artificial swimmers typically provide one degree-of-freedom (DOF): that is, they can swim along a straight line, forward and backward. So far, direction control generally has been performed with altering the external field that drives the microrobot. Thus, the physics of reorientation in microorganisms is of interest to engineers seeking inspiration for the control of artificial microswimmers.

On the other hand, there has been a growing interest in using bacteria and microorganisms for cargo transport and delivery, for instance, medicine in biomedical in vivo and in vitro applications [30-35]. This review, covering the reorientation strategies of several kinds of microorganisms, can shed some light on how to control these organisms for applications in cargo transport.

Because of the vast number of swimming microorganisms, our goal is not to provide a comprehensive review for biologists, but to provide engineers with microswimmer control methods and physics that may have applications in the micro-/nanorobotic field. The rest of this paper is organized as follows. Section 2 describes the swimming methodologies of organisms in low Re number flow and briefly discusses the related hydrodynamics. Section 3 describes the methods used by microorganisms for direction change. Section 4 examines microrobot propulsion systems and proposes methods for direction control in swimming. Section 5 discusses the effect of neighboring solid boundaries on microswimmers. Finally, section 6 summarizes the paper and outlines future possible research directions.

\section{Propulsion of microorganisms}

\subsection{Hydrodynamics of swimming at low Reynolds number}

To distinguish between swimming mechanisms at low and high Re numbers, we briefly explain the hydrodynamics in low Re number flows. Assuming an organism is moving in a fluid, any movement of the body will cause a change in the surrounding fluid. The Navier-Stokes equations describe the fluid dynamics of the swimming microorganism by solving for the flow field velocity, $\mu$ These equations are derived from the conservation of the momentum, mass, and energy for an element of the fluid with an arbitrary finite volume, called the control volume. For an incompressible Newtonian fluid with a constant density, $\rho$, and constant kinematic viscosity, $v$ the Navier-Stokes equations are given by:

$\frac{\partial u}{\partial t}+u \cdot \nabla u+\frac{1}{\rho} \nabla p=\nu \nabla^{2} u+g$

$\nabla \cdot u=0$

where $p$ and $t$ denote pressure and time, respectively, and $g$ is the gravitational acceleration.

If we follow the normalization used by Childress [27], a dimensionless number will appear in Equation (1), which is the Reynolds number [36]. The Reynolds number, $\operatorname{Re}=\frac{u D}{v}$, indicates the ratio between inertial and viscous forces, where $D$ is the characteristic linear dimension. Therefore, a very slow velocity, a small scale flow, or a very viscous fluid results in a very low Re number. In any of these cases, where the $\operatorname{Re}<<1$, the inertia becomes less critical when compared to the viscous forces. For the limiting case, when $R e=0$, the Navier-Stokes equations simplify to the Stokes equation [37]:

$\nabla p=\mu \nabla^{2} \mu$

$\nabla \cdot u=0$

where $\mu$ is the fluid dynamic viscosity.

The Navier-Stokes equations contain time-dependent parameters, while the Stokes equation has no dependence on time. Consider an object in the fluid with a reciprocating motion and a forward stroke that is faster than the backward stroke. At high Re numbers, the quicker forward stroke generates a change in momentum and propels the object. However, in low Re number flow, because there is no time-dependent parameter in the Stokes equation, the speed of the symmetrical strokes does not matter. For propulsion, the integral of the force over time is essential. At low Re numbers, this integral is equal for both strokes [5]. Thus, as much as the object moves in one direction during the forward stroke, it runs in the opposite direction during the backward stroke, and the net propulsion is zero. 
Fig. 1 a $E$. coil as a prokaryotic swimming microorganism with helical flagella. b Human sperm as a eukaryotic cell with a single flagellum with whip-like motion. c Paramecium as a ciliated swimming microorganism covered by several cilia, Image copyright Dennis Kunkel Microscopy, Inc.

Drag in low Re number flows depends on the organism's velocity, shape, and orientation. Velocity changes during power and recovery strokes do not contribute to microorganism propulsion. However, microorganisms use both changes in the shape and orientation of their propulsive organelles to thrust their bodies. As a consequence, the reciprocating motion of microorganisms' propulsive organelles is not symmetrical during the power and recovery strokes.

Different theories have been developed for the hydrodynamic analysis of microorganisms. For example, resistive force theory (RFT) provides a simple understanding of how the drag forces are linearly related to velocity in low Re number flows and relates the normal and tangential drag forces to local velocities [13]. The coefficients of the relationship are the normal and tangential drag coefficients, which depend on the fluid viscosity $[13,17,38]$. Both normal and tangential drag forces contribute to the microorganism propulsion, and the difference between them is the basis of drag-based swimming. As shown in Figure 2a., the difference between normal and tangential drag forces equals the net thrust for the microorganism. Slender body theory (SBT) is an alternative theory for more accurately predicting drag forces, mainly when a large cell body exists attached to the flagella. SBT takes into account not only the effect of local velocities but also the hydrodynamic interactions of distant regions [39].

\subsection{Prokaryotic flagellar propulsion}

Propulsion using helical flagella is one of the most widely methods employed by prokaryotes to propel their bodies. Prokaryotes such as E. coli [16], Rhizobium lupini [40], and Salmonella [41, 42] have helical-shaped flagella. The flagella, while in rotation, can be considered as relatively rigid helices, moving with respect to the body [43-45]. A proximal hook connects the flagellum to a molecular motor embedded in the microorganism body, which provides the required flexibility for the filament [45-49]. E. coli, a rod-shaped prokaryotic microorganism with a body length of $2.5 \mu \mathrm{m}$ and a diameter of $0.8 \mu \mathrm{m}$, shown in Figure 1a, has a Re number of $10^{-5}$ when it swims at maximum speed in water [16].

Figure 2a shows a schematic diagram of a microorganism with a helical flagellum. The flagellum rotates at a fixed velocity, and a helical wave propagates along the tail, towards its end. The wave has a constant radius, pitch, and pitch angle. All elements along the flagellum move and push against the water as the helical wave travels. The flagellum's interaction with the surrounding water applies forces to the fluid in
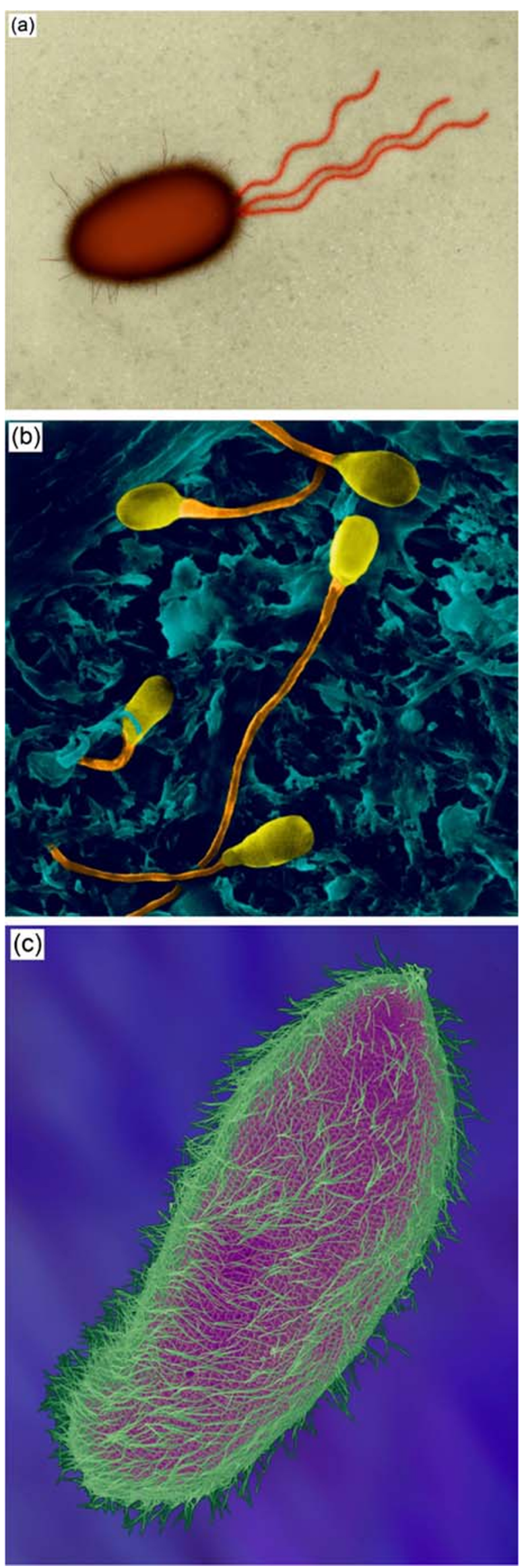


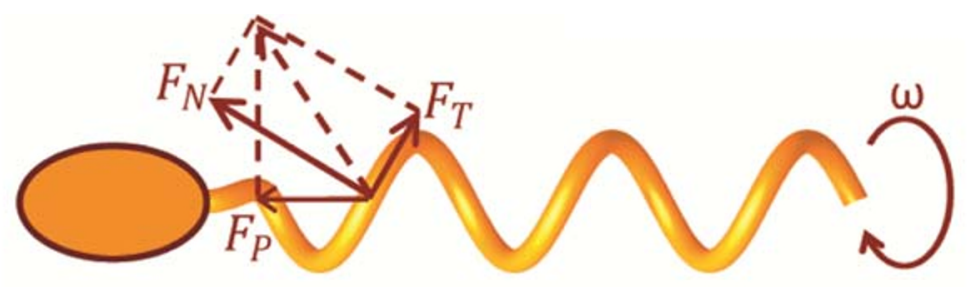

(a)

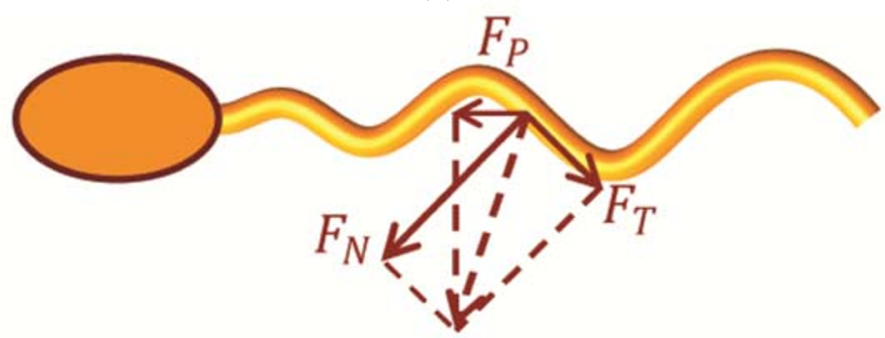

(b)

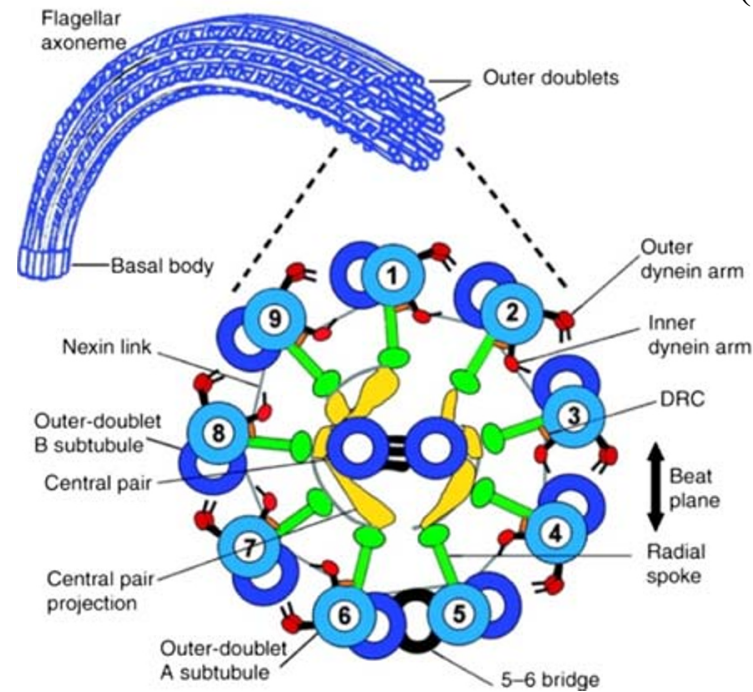

(c)

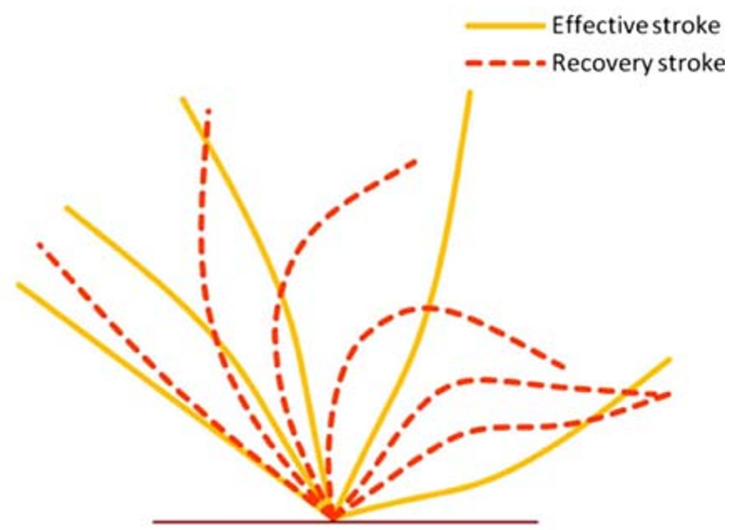

(d)

Fig. 2 a Propulsion mechanism of a prokaryotic microorganism with the rotation of the helical flagellum. $F_{T}$ and $F_{N}$ denote the tangential and normal drag forces, and $F_{P}$ is the propulsive force. $\mathbf{b}$ The propulsion mechanism of a eukaryotic microorganism using wave propagation

directions normal and tangential to the flagellum. The sum of these forces has a component parallel to the helix axis, pushing water to the end of the flagellum. The reaction is in the opposite direction to the flagellum, which drives the flagellum and the attached body. The resulting force has another component in the direction perpendicular to the helix central axis, which generates a torque. This torque is canceled out by the body's rotation because the whole system must be torque-free [50]. The rotation of the cell body reduces the apparent rotation of the flagellum, i.e., its rotational velocity with respect to the water, as well as the propulsion efficiency [25].

A molecular motor, driven by proton or sodium gradients, rotates the flagellum at a typical frequency of a few hundred Hz: for example, $300 \mathrm{~Hz}$ in E. coli [47, 51]. The flagellar

along the flagellum length. $F_{T}$ and $F_{N}$ denote the tangential and normal drag forces, and $F_{P}$ is the propulsive force. $\mathbf{c}$ Cross-section of a eukaryotic flagellum showing $9+2$ microtubules [240]. d Ciliary beating pattern in effective and recovery strokes.

motor can rotate in either direction, counterclockwise or clockwise. The flagellar motor has a rotor-stator structure, similar to electric motors. The ring-shaped components form the stator and rotor of flagellar motors [46, 47, 52]. A flow of protons, due to an electrochemical gradient across the cell wall, drives the motor.

\subsection{Eukaryotic flagellar propulsion}

Eukaryotes use a different shape in flagellar propulsion, although it is again based on drag anisotropy in a viscous environment. A wave, which was considered sinusoidal by Gray [12], but was later shown to be non-sinusoidal [53], travels along the flagellum inducing a vertical motion at any element. 
The movement has components tangential and normal to the element. Motion in each direction results in a force in the same direction applied to the element. However, because the drag coefficients are not equal for the element in the tangential and normal directions, the sum of the corresponding drag forces is not in the motion direction (i.e., vertical) [29]. Indeed, the result has a horizontal component that propels the flagellum and the attached cell (Figure 2b).

Eukaryotic flagella, in contrast to prokaryotic flagella, are active organelles. Nine doublet microtubules, as shown in Figure $2 c$, are arranged around the perimeter of a circle with two central microtubules forming the inner core of a eukaryotic flagellum [15]. Each microtubule is connected to the next one and the central tubule. Dynein arms, located along the flagellum, extend from each of the nine microtubules to the adjacent microtubule. These dynein motors convert the chemical energy to the mechanical movement and allow the microtubules to slide and bend, generating a whip-like motion along the flagellum. For example, human sperm, shown in Figure $1 \mathrm{~b}$, is a eukaryotic cell with a $5 \mu \mathrm{m}$ by $3 \mu \mathrm{m}$ head and a flagellum $50 \mu \mathrm{m}$ long. The typical diameter of a eukaryotic flagellum is $\sim 0.25 \mu \mathrm{m}$, which is constant during flagella movements.

When a planar wave propagates along the flagellum, the motion is different for various elements of that flagellum. Thus, the difference between the normal and tangential drag components varies along the flagellum, producing an inhomogeneous thrust [25]. For a helical wave, however, all elements of the flagellum push against the water at a constant angle. The equal inclination of all elements to the direction of wave propagation generates a homogeneous thrust for a helical flagellum. This thrust homogeneity reduces the energy expenditure for a helical wave when compared to a planar wave along a single flagellum, making the former more efficient [24].

\subsection{Ciliary propulsion}

The ciliates are another group of microorganisms which employ hair-like appendages, called cilia, for swimming. Like eukaryotic flagella, cilia are active organelles with considerably identical 9+2 structure, however, generally shorter in length and more abundant in quantity. The ciliates use a two-stroke motion of cilia to break the time-reversibility at low Re number and propel their bodies. The cilia are straight behaving like a rigid rod during the power stroke and beating on the water. They then bend during the recovery stroke and move tangentially, closer to the body surface, having a minimal effect on the water. The normal drag coefficient is higher than the tangential one, and the cilia move faster during the power stroke [17]; consequently, net propulsion is generated for the microorganism opposite to the cilia beating direction in the power stroke. Figure $2 \mathrm{~d}$ shows a typical pattern of cilia motion during power and recovery strokes. A similar mode is utilized by the flagellate Chlamydomonas [54]; however ciliates can swim faster than flagellates, at a typical speed of 1-2 $\mathrm{mm} \mathrm{s}^{-1}$ [55]. A ciliate Paramecium, depicted in Figure 1c, has a length of 100-350 $\mu \mathrm{m}$ and 3000-6000 cilia.

Cilia have the same axonemal structure as eukaryotic flagella; however, they are shorter, with typical lengths of 5-10 $\mu \mathrm{m}$. The active internal construction of the cilia generates the required bending in the recovery stroke. In contrast to the low numbers of flagella that flagellates have, several arrays of cilia cover the ciliate microorganism's body. Thus, ciliates swim faster than flagellates simply because they have more propulsive organelles. Also, ciliates owe their higher speed to a phenomenon that occurs when the cilia beat in arrays. Each cilium hits with a phase lag relative to the previous cilium, causing a traveling wave at the tips of the beating cilia. This wave, known as a "metachronal wave," is believed to aid ciliates" propulsion $[56,57]$ and to be the result of hydrodynamic interactions between adjacent cilia [58-60].

\section{Reorientation strategies in microorganisms}

Microorganisms respond to many environmental parameters, such as changes in light, chemical substances, energy levels, and moisture. These changes attract or repel organisms with different tendencies, and a change in a given environmental condition may attract one organism while repelling another. Indeed, the way that microorganisms respond to environmental states varies between organism categories or even within a group. For example, flagellates with diverse propulsion mechanisms respond dissimilarly to stimulation. Chlamydomonas orients away from high-intensity light [61-63] and E. coli moves towards chemical attractants [64-68], showing phototactic and chemotactic responses, respectively.

"Taxis" is a directional movement along a gradient, towards an attractant stimulus or away from a repellent stimulus $[69,70]$, the former is known as positive taxis while the latter is known as negative taxis. For example, the ciliate Fabrea salina shows positive phototaxis [71], while Chlamydomonas exhibits both positive and negative phototaxis in the presence of light with a lower and higher intensity, respectively [63, 72]. In contrast to chemotaxis [73, 74], a microorganism response can also be due to an intracellular stimulus, for example, in energy taxis $[75,76]$. Other tactic responses such as galvanotaxis, magnetotaxis, thermotaxis, aerotaxis, rheotaxis, and thigmotaxis can also be employed for navigation and control of bacteria [77]. For example, in galvanotaxis or magnetotaxis, applying an electric or a magnetic field, respectively, can steer the movement of bacteria either towards or away from the stimulus. The thermotactic response of organisms is defined by regulating their action depending on a heat source; for instance, E. Coli moves towards hot areas in the absence of chemicals [78]. 
Magnetotactic bacteria (MTB) are flagellated cells that use their specific magnetic organelles, called magnetosomes, to align themselves along magnetic field lines [79]. These organisms also exhibit an aerotactic response preferring microaerobic or anaerobic environments as they typically migrate towards a low oxygen concentration [80]. Rheotaxis, a directed motility due to a flow shear, has been reported in bacteria and can be exploited for navigation of biohybrid microswimmers [81, 82].

However, the response of microorganisms to stimuli is not always a directional movement; instead, it is an exertion to stay in a desirable state or to leave an undesirable one. Such a move is called "kinesis," which can be seen as a sustained speed increase in a cell of Rhodobacter sphaeroides [83] or a cell population of Azospirillum brasilense [84]. They increase or decrease the speed of their random movements without any orientation.

With either random or directional movement, microorganisms need to orient to find food and energy sources. They also need to change orientation to escape from threats. Next, we review the orientation and navigation of microorganisms.

\subsection{Tumbling}

Flagellates with peritrichous flagella have several $(4-8)$ thin filaments arranged randomly on the cell body. A random and asymmetric distribution of flagella might increase cell motility and chemotactic performance [85]. Escherichia, Salmonella, and Bacillus are among the bacterial genera with peritrichous flagella [86-88]. Each flagellum has its own molecular motor $[42,47]$, enabling the flagella to rotate independently. The motors spin in a reversible manner; thus, flagella can rotate in a counterclockwise $(\mathrm{CCW})$ or clockwise $(\mathrm{CW})$ sense. The standard rotation sense of flagella is determined when they are viewed from the distal end, towards the cell body [47].

The standard shape of a flagellum is a left-handed helix [89]. Microorganisms with peritrichous flagella gain their motility from CCW rotation of left-handed helical flagella. When flagella start to spin in a CCW sense, the hydrodynamic interactions form a bundle of flagella, usually around the longitudinal axis of the body [90-94]. Indeed, the importance of body rotation on developing a flagella bundle has been recognized [95]. The helical bundle of flagella propels the microorganism forward in a relatively linear trajectory. This forward motion is known as a run or smooth swimming. The $E$. coli speed during the run stage, depending on the stimulation state, is $\sim 30 \mu \mathrm{m} \mathrm{s}^{-1}$ [64].

The run stage is interrupted by a "tumbling" effect when one or more flagella start to rotate in a CW sense. These flagella leave the bundle; thus, the force balance of the flagella is no longer in the forward direction, resulting in an in-place rotation of the body, as depicted in Figure 3a. The flagella undergo polymorphic transitions, forming right-handed helical flagella. Tumbling occurs due to the $\mathrm{CW}$ rotation and polymorphic transformations of flagella and leads to a change in swimming direction [89, 96-98]. By running and tumbling, a microorganism exhibits a randomized motion or "random walk" during which it cannot precisely control its orientation. However, these seemingly haphazard movements, which can be explained by Brownian motion [99], will result in biasing the organism in the direction of increasing an attractant or decreasing a repellent. To move in the desired direction, bacteria regulate the number of tumbles so that the number decreases when moving up an attractant gradient and increases when shifting down. Recently, it has been shown that bacteria tune their direction not only by changing the number of tumbles but also by adjusting the rate of angle change between two runs [100-102]. Vladimirov et al. proposed that the rotational angle during a tumble can be regulated by the number of motors that rotate clockwise [100]. They showed that when an organism needs to change direction rapidly, more motors are driven in the $\mathrm{CW}$ direction.

In a tumble, the flagella's polymorphic transition accompanies the rotation reversal, forming helical shapes with different geometrical characteristics to the normal ones [88, 103]. Figure $3 \mathrm{~b}$ shows an E. coli flagella leaving the bundle and undergoing polymorphic transformations, which leads to a reorientation for the cell body. Then, the cell swims in a new direction when the flagella again form a bundle. Kitao et al. proposed that the polymorphic transitions are due to energy frustration between flagella [104]. Transitional flagella are right-handed helices of shorter wavelengths - for example, in the case of Salmonella, $1.1 \mu \mathrm{m}$ - while normal ones are left-handed helices of wavelength $2.3 \mu \mathrm{m}$ [88]. Structural changes in flagella, from normal to curly, along with flagella rotation reversal, are believed to cause bundle dispersal and tumbling. Macnab and Ornston proposed several reasons that may be responsible for a microorganism's erratic motion in a tumble, such as propagation of the polymorphic transition along the flagella rather than an instantaneous change, a large pitch angle during the polymorphic transition, and various wave propagation rates in the flagella [89]. Thus, having multiple flagella assists peritrichous cells in changing direction more effectively, rather than increasing the cell velocity, because a bundle of several flagella contributes only slightly to a faster cell motion [105].

\subsection{Reverse and flick}

Monotrichous flagellates have a single flagellum at one or both poles of the body, in parallel with the central axis. Possessing a single polar flagellum, Vibrio alginolyticus outruns $E$. coli with its multiple flagella in chemotactic responses because it swims faster towards and along a chemical attractant gradient [106]. Counterclockwise rotation of the left-handed helical flagellum results in a forward motion of $V$. alginolyticus, while motor reversal generates an opposite backward movement. However, 
Fig. 3 a Run and tumbling of a peritrichous flagellate. The flagella form a bundle during CCW rotation of the flagellar motors and push the body forward. This run stage is interrupted by rotation reversal of one or several flagella, resulting in the tumbling of the cell. The cell changes its swimming direction and then runs in the new direction. b Run and tumble of an E. coli cell. The numbers show the frame number of images taken at a frequency of $60 \mathrm{~Hz}$. Some flagella leave the bundle (starting at frame 6) and undergo a polymorphic transformation (frame 14). Hence, E. coli tumbles and reorients in a new direction [98].

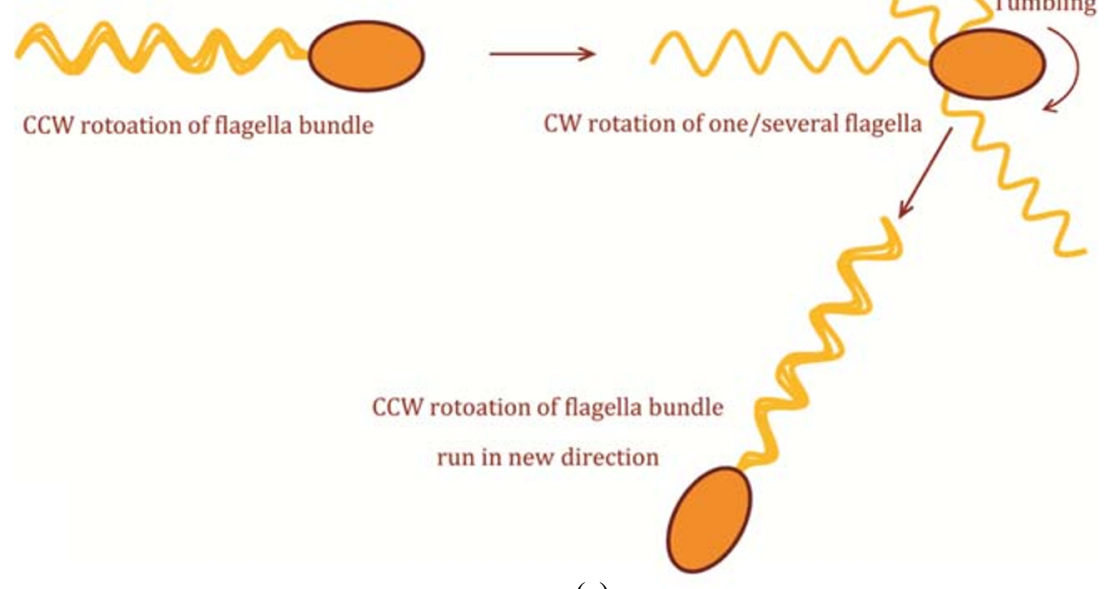

(a)

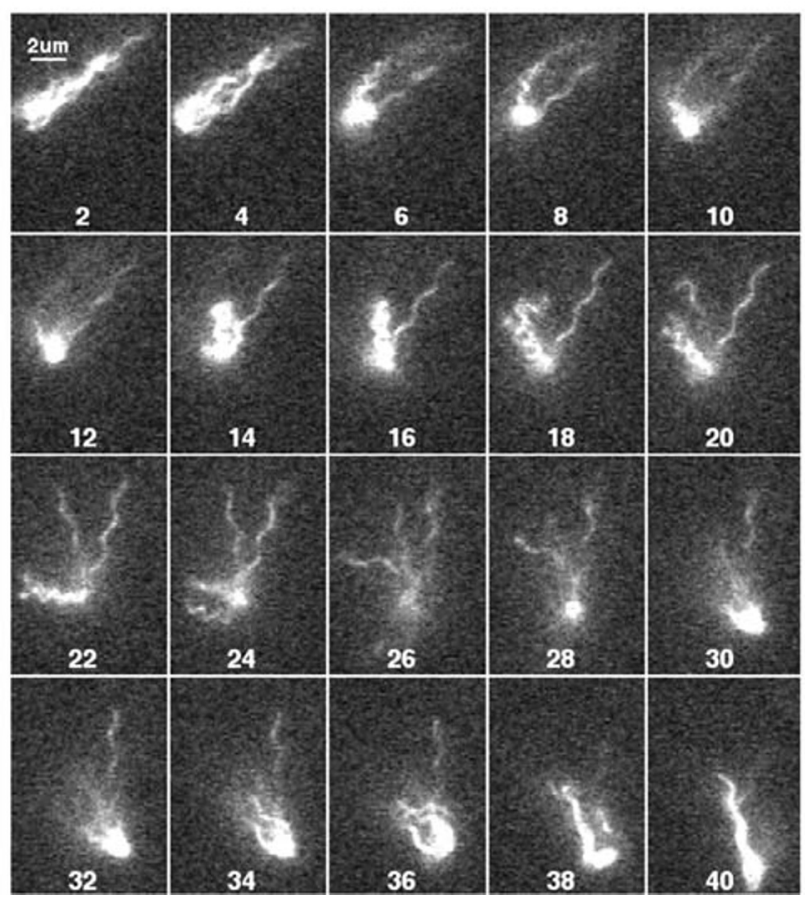

(b) the flagellum of $V$. alginolyticus exhibits neither a polymorphic transition nor a handedness change during $\mathrm{CW}$ rotation. The microorganism can reach a maximum swimming speed of $150 \mu \mathrm{m} \mathrm{s}^{-1}$ when the flagellar motor rotates at 1700 revolutions per second (rps) [107, 108].

Forward-backward motion was previously reported for the single flagellum Pseudomonas citronellolis by Taylor and Koshland [97]. They believed that motor reversal resulted in the backtrack of the cell body and changed the cell direction. This understanding seemed appropriate, especially when the organisms swam near a surface; the wall drag could cause a difference between forward and backward trajectories, resulting in a direction change [109-111]. However, more recent studies have shown that the chemotactic response is possible not only near a surface, but also $500 \mu \mathrm{m}$ away, because the organism's smooth swimming is, in fact, reoriented frequently [106, 112]. Figure 4a shows sequential video images of $V$. alginolyticus moving in the fluid and redirecting using its single flagellum. The motion and reorientation of monotrichous $V$. alginolyticus is described as a three-step motion: run-reverse-flick, as schematically shown in Fig. 4b $[106,113]$. Run or forward motion is followed by a 180 - 

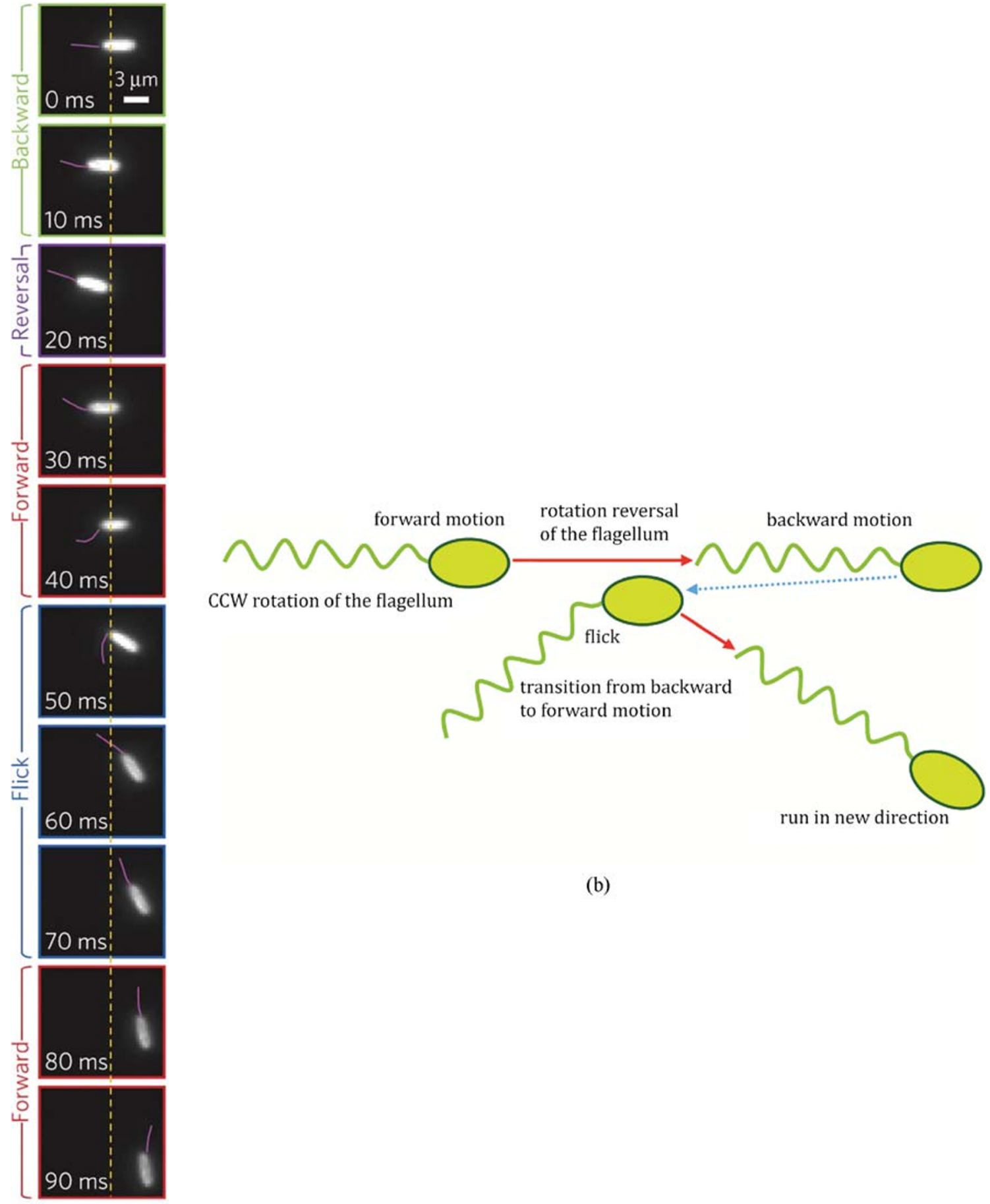

(b)

(a)

Fig. 4 a Sequential images, taken at a frequency of $420 \mathrm{~Hz}$, show how $V$. alginolyticus reorients by a three-step motion, including forward, backward, and flick of the flagellum. The images show the flagellum (magenta) before, during, and after a flick, and the cell body (white) as well. The position of the cell can be distinguished using the orange reference line [115]. b Run, reverse, and flick of a monotrichous flagellate.

degree backtrack towards a reverse motion, and then a forward motion concurrent with a flick, i.e., a turn with an angle of less than $180^{\circ}$. The flick stage shifts the organism to a new

CCW rotation of the single flagellum generates a forward motion for the organism. Then, the flagellar motor rotates in a reverse direction, which leads to a backward movement. This backward motion is followed by a simultaneous forward motion and the flagellum flick and reorients the microorganism. The flagellum CCW rotation propels the cell in a new direction.

direction in which the cell begins another forward motion phase. Substituting tumbling in peritrichous prokaryotes, which, for example, takes $\sim 0.23 \mathrm{~s}$ in $E$. coli [114], a flick in 
monotrichous counterparts occurs more rapidly: for example, in less than $0.1 \mathrm{~s}$ for $V$. alginolyticus [106]. The flick causes the cell to change direction at an angle with a normal random distribution and a mean value of $90^{\circ}$ [106]. This reorientation mechanism is very effective for marine microorganisms living in the transient environment of the oceans and leads to a fast chemotactic response.

Recently, a report by Son et al. suggested that the flick was due to a buckling instability of the hook at the flagellum base [115]. The hydrodynamic force and torque that buckle the hook depend on the swimming velocity. With increasing velocity, the buckling force exceeds some threshold, and the hook exhibits instability. The standard swimming velocity of $V$. alginolyticus is around the threshold velocity, imposing instability in the flagellum hook [115]. They showed when the microorganism swimming velocity is reduced from the standard value of $47 \mu \mathrm{m} \mathrm{s}^{-1}$ to $25 \mu \mathrm{m} \mathrm{s}^{-1}$, the flicking probability drops by around $60 \%$. During forward motion, a flagellum hook is under a torsional load and is stiff enough to prevent instability. Motor reversal winds off the hook, so it becomes prone to instability. Thus, the microorganism uses its flagellum not only as a propeller but also as a rudder to steer, albeit randomly [106].

\subsection{Helical-path swimming}

Run and tumble, and reverse and flick are only observed as navigation tactics in small bacteria. However, sperms [116-119] and larger bacteria such as Thiovulum majus [120], eukaryotic flagellates [121, 122], and ciliates [123, 124] swim along smooth trajectories of helical shape. Swimming in these cells and organisms is described by translational and rotational motions of the body. With constant velocities, once the rotational velocity vector is parallel or perpendicular to the translational velocity, the swimming trajectory is a line or a circle. Otherwise, the trajectory is a helical path with a straight central axis parallel to the body's net swimming direction (Fig. 5a) $[125,126]$. Although the direction of the axis of the helical trajectory depends on the rotational and translational velocities and their first and secondtime derivatives, when the speeds are constant, this axis is parallel to the rotational velocity of the body. This simplifies the analysis of the motion and orientation of the cell [127].

Crenshaw assumed the organism's soma to be a rigid body and described its swimming along a helical path [128]. In the coordinate system ijk, which is shown in Fig. 5b, fixed to the right-hand helical trajectory, with $\mathrm{k}$ as the helix axis, the position vector of the path's endpoint, which coincides with an arbitrary point in the organism body (e.g., the center of mass), is given by:

$\mathbf{H}(\mathrm{t})=r \cos \alpha t \mathbf{i}+r \sin \alpha \mathbf{j}+\left(\frac{h \alpha t}{2 \pi}\right) \mathbf{k}$ where rand $h$ are the radius and pitch of the helix, and $\alpha$ is the rotational frequency of the position vector. The organism's motion can also be explained in a tangent-normal-binormal coordinate system, TNB, where the organism's linear velocity - i.e., the time derivative of Equation (3) - is given by $\mathbf{v}=V \mathbf{T}$. Crenshaw defined a Darboux vector, $\mathbf{d}$ which is perpendicular to the unit vector $\mathbf{N}$ as [127]:

$\mathbf{d}=\tau \mathbf{T}+K \mathbf{B}$

where $\tau$ and $\mathbf{K}$ are the torsion and curvature of the helical trajectory, respectively. Crenshaw demonstrated that the vector $\mathbf{d}$ is parallel to the helix central axis, which lies in the kdirection. Because the vector $\mathbf{d}$ changes direction with respect to the $T$-axis as a function of the ratio $k / \tau$ (see Equation (4)), the helical trajectory axis also changes direction with changes in this ratio (see [128] for more detail). We can conclude that because the torsion and curvature of the organism's trajectory are functions of its translational and rotational velocities, the organism orients its swimming direction by changing these velocities. However, Crenshaw demonstrated that translational velocity changes do not affect the organism's orientation (except under specific conditions where it has a transient effect), and spatial reorientation occurs when there is a change in rotational velocity with respect to the organism's body [128]. For example, an increase in the rotational speed of the organism can result in a net direction change. However, if variation in the rotational velocity occurs with an increase in the linear velocity, then reorientation will be faster [129].

Changes in the direction of a microorganism's rotational velocity are recognizable by variations in its helical trajectory parameters, such as radius, pitch, and pitch angle [128]. For example, in Paramecium, a transformation of the organism's helical path to a more linear trajectory, due to the rise in the beating rate of cilia leads to the orientation of the Paramecium [130]. This transformation indicates that the microorganism has changed its rotational velocity. Fig. 5c shows how Paramecium changes the parameters, including pitch angle and diameter of the helix, of its helical swimming path when responding to chemical stimulation.

Microorganisms orient the axis of their helical swimming trajectory to the direction of a stimulus [129], as can be seen, for example, in Chlamydomonas cells [131, 132]. This orientation is performed by changing the components of the rotational velocity of the organism and aligning it with the stimulus direction [117]. Crenshaw demonstrated that if the rotational velocity components are functions of the stimulation intensity - for example, chemical concentrations - then the organism can align its direction with the desired stimulation direction [129].

Another study showed when the torsion and curvature of a swimmer's helical path depend on the stimulation signal, it can orient to exhibit a chemotactic response, referred to as 
Fig. 5 a The motion of the ciliated cell is described using its rotational and linear velocity. If the velocities are not parallel or perpendicular, the trajectory of the organism has a helical shape. The helical trajectory axis shows the direction of motion. The ciliated cell changes rotational velocity, for example, with a rise in the beating rate of cilia, which yields to swimming along a new helical path of an oriented direction to the previous helical trajectory. b The helical trajectory of a microorganism. The coordinate system ijk is used to describe the helical path, which $\mathbf{k}$ is the helix axis. $\mathbf{T}$ and $\mathbf{N}$ show the tangential and normal unit vectors of the tangent-normal-binormal coordinate system (B, which is perpendicular to both $\mathbf{T}$ and $\mathbf{N}$, has not been shown). c Images of a Paramecium helical swimming paths of different shape which responds to a chemical stimulation (solution of $20 \mathrm{mM} \mathrm{KCI)} \mathrm{[130].}$ Paramecium swims backward along the helical path 1 to a stop at position 2. Then, its motion transforms to a circular one at 3 , and gradually to helical paths which are close to a linear motion at 7 [130].
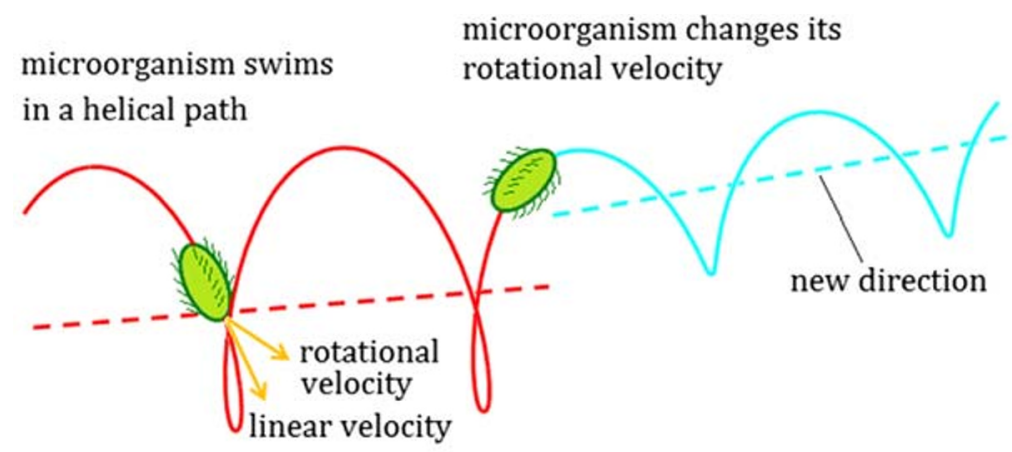

(a)

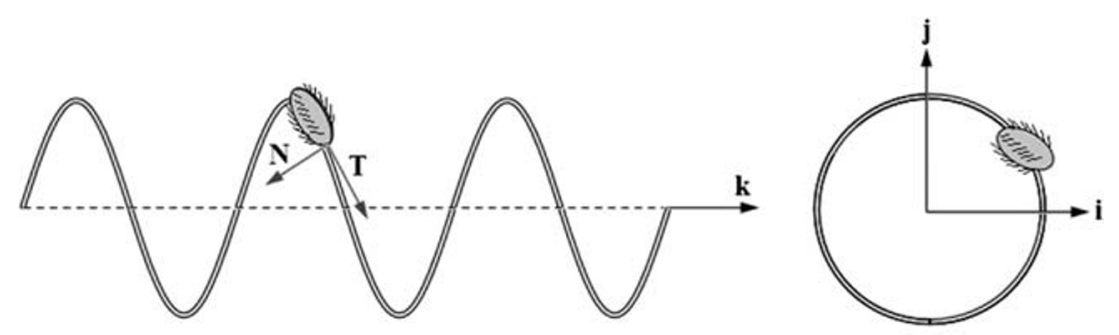

(b)

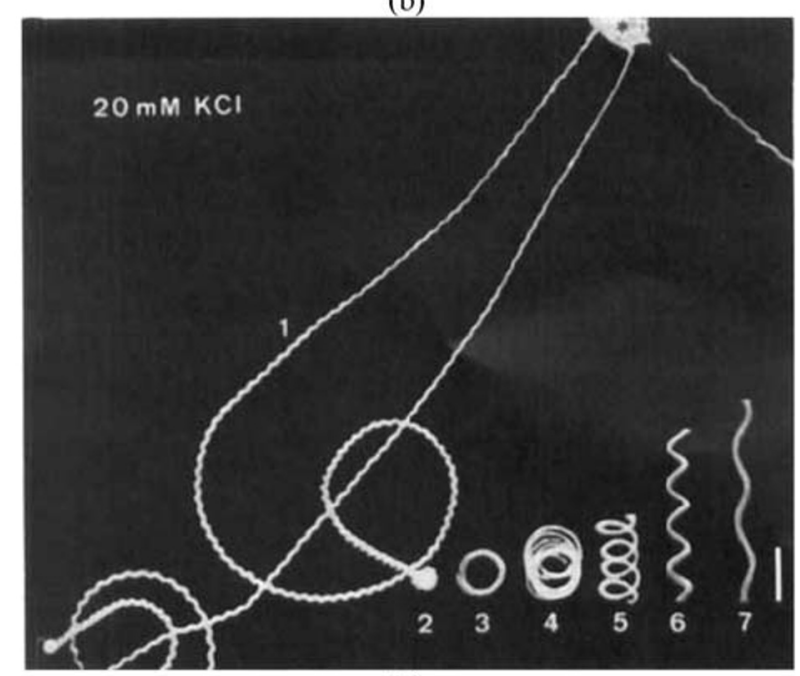

(c) helical klinotaxis [133]. Recently, Su et al. claimed that human and horse sperms swim along a helical band, instead of a helical path, having a sinusoidal motion in the plane of the band [119]. However, this combined motion, oscillation along a "chiral ribbon," does not change their overall helical motion or the way they orient.

\subsection{Orientation by speed modulation}

In contrast to a direction change in the rotational velocity of a motor in tumbling, or of the body in helical swimming, some microorganisms use a rate modulation for reorientation. Rhodobacter sphaeroides has a single flagellum protruding laterally in the middle of its body that rotates in only one direction, usually CW [134]. Clockwise rotation of the flagellum, which has a right-handed helical shape with a small amplitude and long wavelength, propels the organism forward along a straight line. The regular swimming is interrupted by stops where the organism reduces the rotational speed of the flagellum and changes the swimming direction. Packer et al. showed that the flagellar motor of $R$. sphaeroides varies its speed from a mean value of $6.9 \mathrm{~Hz}$ during a run to less than $3 \mathrm{~Hz}$ in the stop phase, and vice versa [135]. This deceleration and acceleration can be regulated at different rates. When the motor reduces its speed during a stop, the flagellum exhibits a polymorphic transition to a large-amplitude, smallwavelength curly helix [136]. The slow rotation of this curly flagellum does not propel the cell, but it contributes to the 
reorientation [137]. Exploiting this orientation method, shown in Fig. 6a, R. sphaeroides can exhibit a chemotactic $[138,139]$ or a chemokinetic [140] response under certain conditions.

$R$. lupini, shown in Fig. 6b, has four flagella rotating only in $\mathrm{CW}$ sense, contrary to the bidirectional rotation of $E$. coli flagella [40]. Once all flagella rotate in a CW direction, the bundle of flagella creates a forward motion for the R. lupini. After this run stage, one flagellum slows down, and the bundle spreads out when the cell reorients (Fig. 6b). R. lupini swims in a new direction by reforming a bundle of flagella.

Reorientation by speed modulation is also seen in Sinorhizobium meliloti $[141,142]$. S. meliloti has peritrichous right-handed "complex" flagella that differ from the "plain" flagella of E. coli. Complex flagella have a coarse surface consisting of grooves and helical ridges compared to the smooth surface of plain filaments [143]. The flagellar motors of $S$. meliloti are unidirectional and rotate in the $\mathrm{CW}$ direction. When motors speed up in the $\mathrm{CW}$ direction, the flagella form a bundle and propel the cell at a velocity of up to $60 \mathrm{\mu m} \mathrm{s}^{-1}$ [144]. In a chemotactic response, the rigid structure of the complex flagella does not allow a polymorphic transition, and the flagella continue to rotate in a CW direction. However, they start to turn at different rates, with slower rates for some flagella [145], leading to dispersal of the flagella bundle and changes in the swimming direction of the cell. The cell turns occur continuously between runs, without an evident stop, in contrast to that seen in R. sphaeroides, by speed modulation and asynchronous rotation of flagellar motors [138].
Fig. 6 a The microorganism changes direction by speed modulation. Forward swimming of the cell due to $\mathrm{CW}$ rotation of its single flagellum is interrupted by rotational speed reduction and polymorphic transition of the flagellum. This leads to a reorientation of the organism and swimming in a new direction. b Successive images, taken at 60 $\mathrm{Hz}$, of $R$. lupini having four flagella rotating in $\mathrm{CW}$ direction, which moves the cell forward (frame 1). One flagellum slows down rotation at frames 2 to 5 when it starts to leave apart the bundle (shown by a white arrow in frame 5). The flagellum ends in a stop in frame 9 (shown by white arrow), causing a reorientation for the cell, which is complete in frame 11 . The bundle is reformed in frame 12 to 15 where the cell swims in a new direction [40].

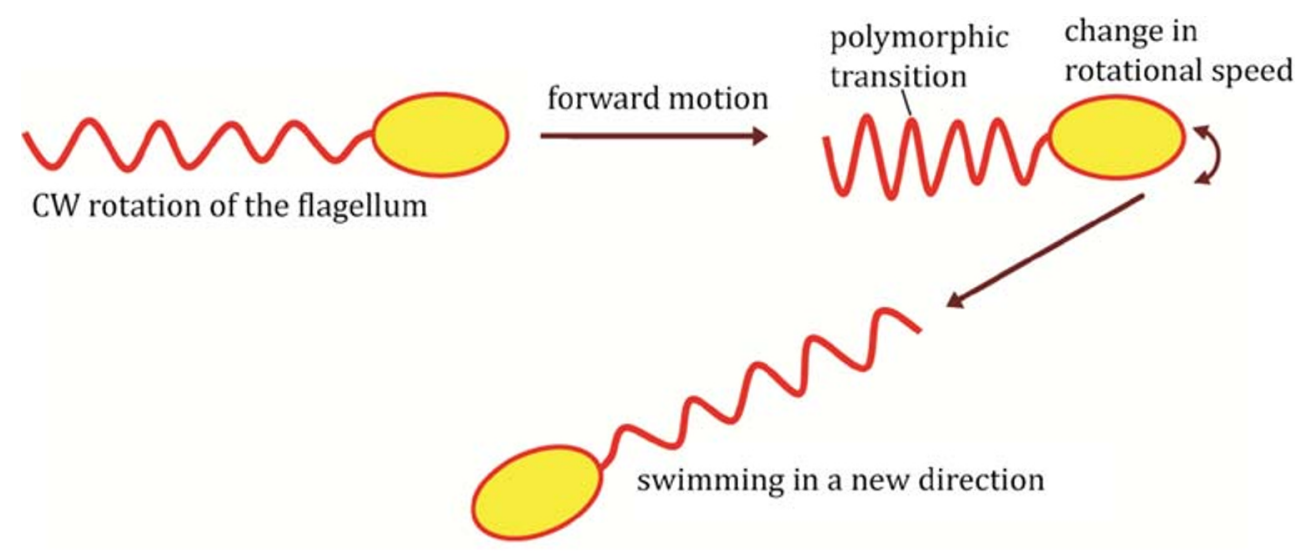

(a)
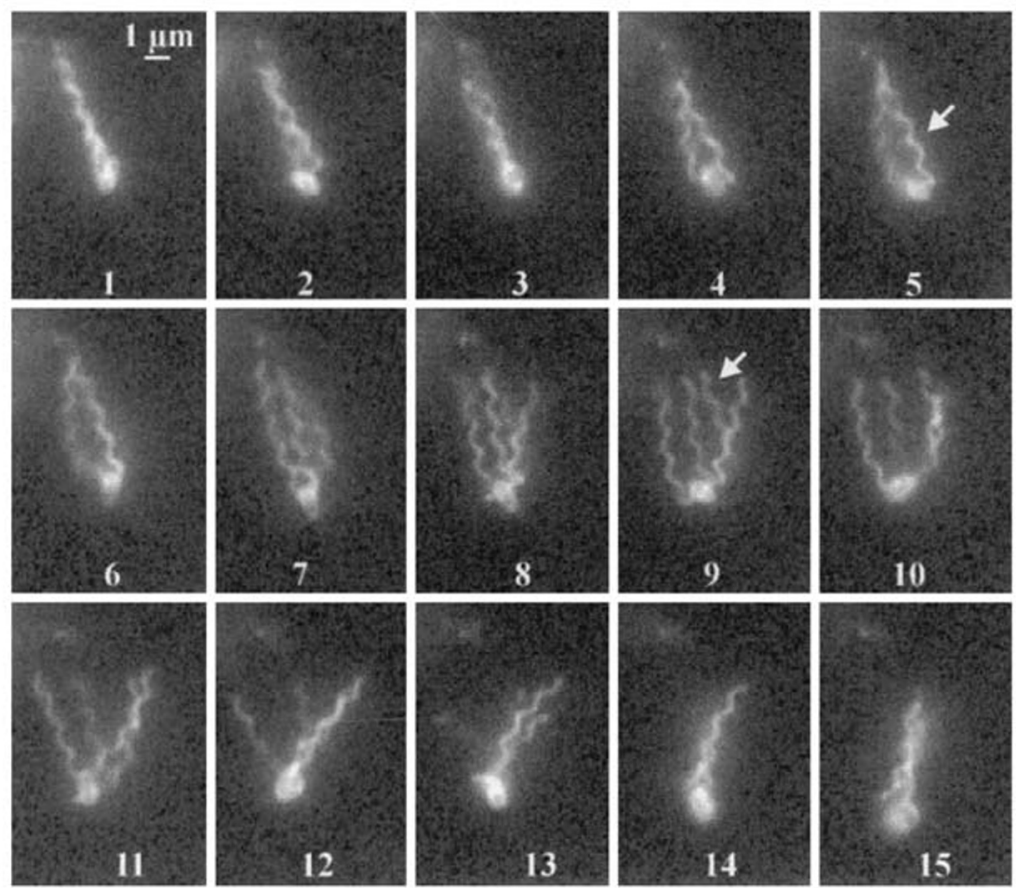

(b) 


\subsection{Complex flagella}

$R$. lupini changes its swimming direction by speed modulation of its peritrichous flagella when the flagella clockwise rotation is followed by an asynchronous deceleration and bundle dispersion, as described for S. meliloti above [40]. The speed modulation is accompanied by perturbations at the flagella tip that propagate along the bundle. This phenomenon is thought to break the hydrodynamic unity of the bundled flagella and to contribute to the reorientation of the organism (Fig. 7) [146, 147]. The complex flagellar filaments of R. lupini, similar to flagella of S. meliloti [148], are helically perturbed, with a coarse surface and outer ridges [149-152]. This specific outer structure of the flagella, which is an adaptation to a highly viscous environment, causes perturbations, and may deviate the laminar flow (intrinsic at low Re number) to a surprisingly turbulent flow [147]. Trachtenberg et al. modeled the flow over the filaments of $R$. lupini, which have a specific cross section (Fig. 7), and found theoretically that the flow will become turbulent at the leading edges of the complex flagella [147]. This transition emerges at Re numbers of 0.015 or higher which real flagella may experience, albeit at utmost conditions. Although this is a local effect at the flagella surface, the turbulence might be sufficient to break the hydrodynamic integration of the flagella and disperse the bundle. When the flagella bundle is disunited, the cell changes swimming direction during a short tumble. Then, the flagella start to rotate again with concerted speeds and form a bundle, propelling the organism in the new direction.

\subsection{Effects of mastigonemes}

Eukaryotic flagellates, such as spermatozoa, are usually pushed when planar waves travel along the flagellum's length. However, the anterior flagellum of the Ochromonas malhamensis pulls the cell, and its undulating waves propel the cell in the same direction [153-158]. This thrust reversal is related to the effect of lateral hair-like projections, called mastigonemes, along the flagellum. The mastigonemes have a typical length of $1 \mu \mathrm{m}$ and a diameter of $20 \mathrm{~nm}$, and are seen on at least two sides of the flagellum [50]. Jahn et al. explained that these passive mastigonemes function when they are relatively stiff or oriented in a desired direction [153]. Their hydrodynamic analysis showed that the thrust reversal was seen beyond a critical number of mastigonemes; however, with the critical number of mastigonemes, the cell becomes non-motile. Holwill and Sleigh explained that the greater tangential drag coefficient of flagella bearing mastigonemes, compared with the normal coefficient, leads to codirectional wave propagation and cell propulsion [154]. They found that for a flagellum with two rows of mastigonemes, the ratio between the tangential and normal drag coefficients was 1.8 , while the ratio was 1.2 in the case of flagellum with nine rows of mastigonemes.

\section{Micro-/nanorobot control}

Engineers have benefitted from progress in understanding the physics of microorganisms, and have been inspired by the locomotion methodologies of these tiny creatures to propose several micro- and nanorobots exploiting flagellar and ciliary propulsion methods. Although the field has advanced predominantly in only the past decade, there are some reviews of the area [159-165]. Reviewing the literature shows that mimicking biological patterns has been a dominant strategy to develop functional swimming microrobots [164].

Peyer et al. reviewed artificial bacterial flagella (ABF) microrobots that mimic prokaryotic flagellar propulsion [160]. Helical propulsion using rigid or flexible filaments has been used as a mechanism for artificial microswimmers [166-175]. The microswimmer, consisting of a helical
Fig. 7 Schematic illustration of $R$. lupini propulsion and orientation. Bundle of flagella rotates in $\mathrm{CW}$ sense to propel the cell. Slowing down the rotation of one flagellum causes the flagella bundle to fly apart. The turbulent flow formed at the tip of complex flagella contributes to this flagella dispersion. The inset shows the cross-section of complex flagella of R. lupini [150].

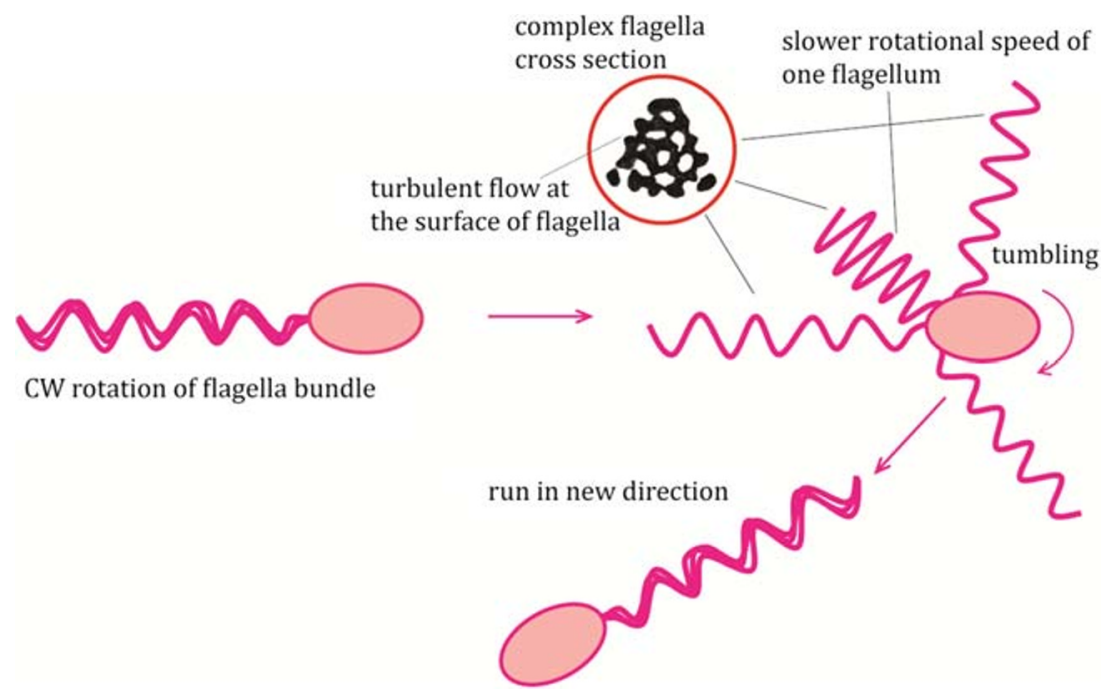


filament and a body, is rotated under an external field, typically magnetic. The external field can spin a magnetic head or a magnetic flagellum, and hydrodynamic interaction between the helix and the fluid converts the rotational motion to a linear one degree-of-freedom (DOF) motion of the microrobot. Using three-dimensional direct laser writing, Tottori et al. fabricated a helical structure that could achieve a maximum speed of $320 \mu \mathrm{m} \mathrm{s}^{-1}$ [169]. This group later reported similar structures composed of a degradable superparamagnetic polymer with comparable motion characteristics [176]. They have proved the potential of functionalized ABF microrobots for various biomedical applications, for instance, gene therapy [177]. Another rigid helical magnetic robot has been fabricated by $3 \mathrm{D}$ molding of iron structures in the range of few micrometers [178]. Recently, instead of hard and stiff materials, some microrobots are made of soft and flexible helices or biohybrid structures $[179,180]$. For example, helical biohybrid microrobots have been reported by magnetizing microalgae organism maintaining its motility for targeted therapy [179]. Furthermore, soft microrobots depict swimming capabilities such as 3D-printed hydrogel-based microrobots under applying an external magnetic field [180] or a photothermal actuation [181].

Eukaryotic propulsion systems have also been used for human-made swimmers at microscale [182, 183]. Fig. 8 shows a flexible flagellum that has been stimulated to generate a wave traveling along the flagellum and hence, propels the head. The flagellum is composed of magnetic micro-spheres connected with flexible DNA linkers [182]. Guo et al. actuated a magnetic head attached to a flexible flagellum by an alternating magnetic field $[184,185]$. The robot had a millimeter-scale and could move in the water. Even though this idea should be tested at a microscale to demonstrate the propulsion ability in low Re number flow, it has one-DOF motion. Another approach is to stimulate piezoelectric segments of the flagellum with a phase difference to form a planar wave [186, 187]. Ahmed et al. suggested propelling a nanoswimmer by acoustically triggering its flexible tail and creating a traveling wave through it [188]. Recently, Khalil et al. have reported a magnetic microrobot that exploits the planar wave of two soft flagella for swimming forward and backward [189].

Ciliary propulsion shows potential for artificial microswimming [190-194]. Ghanbari et al. proposed a magnetic actuation of artificial cilia using a pre-designed field and demonstrated a beating pattern of cilia, mimicking their natural counterparts [191]. Although this cilia-based microrobot did not benefit from forming a metachronal wave because the cilia beat with identical frequency and without a phase difference, it showed appropriate swimming efficiency [190]. The synchronous beating of two rows of cilia, distributed symmetrically on the body sides, generated a one-DOF motion in the microrobot.

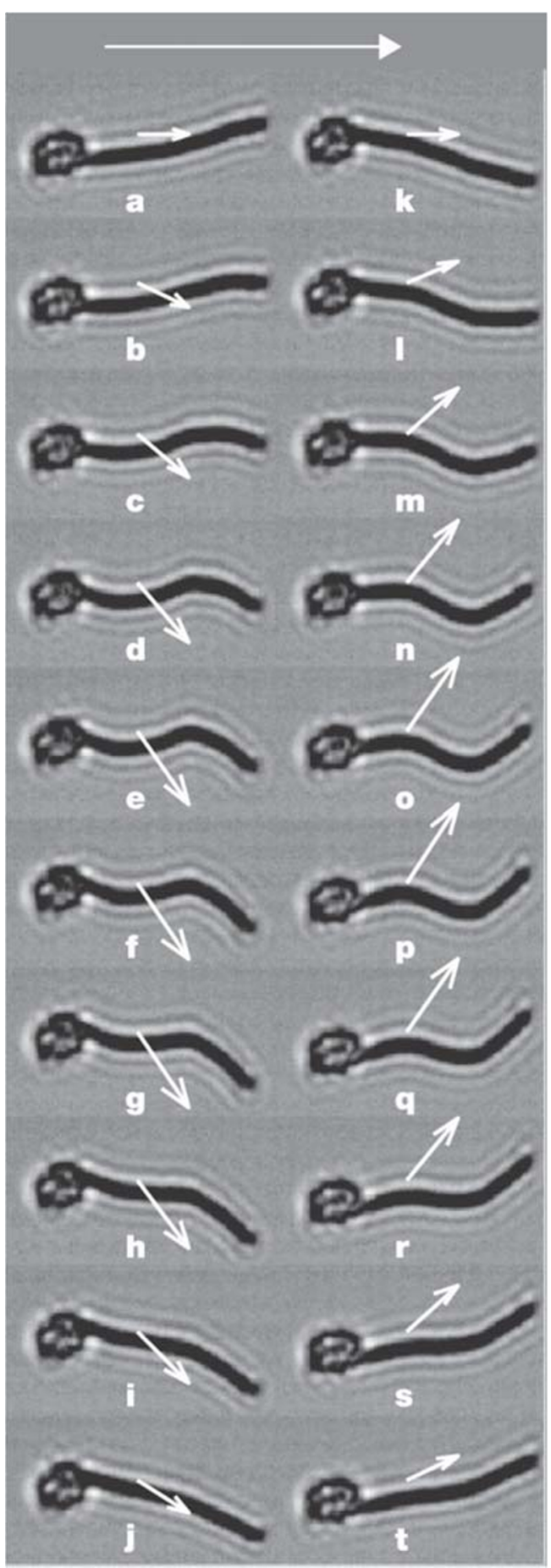

Fig. 8 The whip-like motion of the flexible flagellum, composed of magnetic micro-spheres connected through DNA joints, propels an attached red blood cell [182].

The most conceivable application of swimming microrobots is in medicine, where microrobots may be able to operate in difficult-to-access regions inside the human body $[161,195,196]$. Nelson et al. listed potential areas for microrobot use, such as blood vessels, the spine, and the urethra [197]. These fluid pathlines usually have complex threedimensional geometries. For practical use, the microrobots 
should be able to follow complex trajectories of bodily fluid paths. Thus, they would require an orientation capability along with propulsion. Microrobot orientation control systems proposed in the literature have typically been realized by manipulation of an external field that drives the robot $[198,199]$. Here, we propose bioinspired methodologies that may be used for microswimmer reorientation.

\subsection{Tumbling}

Inspired by bacterial flagella, a tumbling effect can be mimicked in artificial helical microswimmers. The closest mimicking method would be to use several helical flagella, each driven by a motor. Theoretically, synchronous rotation of the motors would propel the microrobot on a linear path. This one-DOF swimming could be interrupted by tumbles when one or more motors start to rotate in another direction, causing the microrobot to tumble and change its rotation. Unlike bacteria, the tumbles may not follow a random pattern and can be learned by a control system to generate the desired reorientation. However, this motor-driven system may be difficult to miniaturize.

Most of the helical propellers that have been realized are rigid $[166,167,169]$. The idea is to interrupt the corkscrew motion of rigid helices by tumbling due to a perturbation. A helix can be devised with some flexible appendages, as shown in Fig. 9a. Provided that the filaments are sufficiently flexible, they follow the rigid helix rotation and contribute to propulsion. Once the external field that generates rotational torque is turned off, the flexible flagella will fly apart, causing a force imbalance. This imbalance can lead to the microrobot tumbling and an orientation change.

It is also worthwhile to consider the tumbling of a microrobot with flexible flagella. One or several flexible filaments can achieve a helical shape under torsion that exceeds a bifurcation threshold, transforming flat filaments. As long as the torque is present, the helical filaments push the microrobot forward. By reversing the torque, the microswimmer tumbles and, like real prokaryotic organisms, changes orientation. Polymorphic transitions of flagella, from normal to coiled and curly shapes, have been recently reported for a magnetic nanorobotic swimmer to generate different swimming characteristics [200]. Though tumbling has not occurred for this artificial swimmer because of its variations from real bacteria structure and a low actuation frequency, these polymorphic transformations of flagella can establish a navigation strategy for micro-/nanoswimmers to adopt themselves with a dynamically changing environment.

Multi-actuation strategies would likely provoke coupled effects between the cell body of a microrobot and its flagellum or between its flagella. For instance, introducing a thermal or optical stimulation to a flagellar microswimmer with a cell body composed of physically responsive hydrogels
[201-203], when its flagella are magnetically triggered, can cause a tumbling. Heating these soft materials establishes morphological transformations of the hydrogel-fabricated body leading to a reorientation for the swimmer.

\subsection{Reverse and flick}

The mechanism used by organisms to generate a flick in the flagella could also be copied in artificial microswimmers. Consider a microrobot design composed of a body, a helical flagellum, and a flexible hook that connects the body and the flagellum (Fig. 9b). The helical flagellum acts as a propeller and a rudder to change the microrobot's direction. When the flagellum is rotated by a torque that applies tension in the flexible hook, it follows the flagellum's rotation. Thus, the microrobot moves in a linear path. However, the linear motion of the microrobot can be interrupted by reversing the direction of the helix rotation, causing the hook to undergo compression. Buckling instability of the hook under compression can result in a flick of the flagellum and an orientation change of the microrobot. Buckling instability has been reported previously for elastic filaments spinning in a viscous fluid [204, 205], and has also been shown to be responsible for extensive bending of cilia in an artificial microswimmer [191]. The flexibility of the hook can be designed to provide the desired functionality in the run and orientation phases. In another design, two rigid helices can be connected with a flexible hook to exploit the flick on the attached helix for orientation of the other helix, as shown in Fig. 9c.

The flexibility of the hook and the capacity for a flick will vary with the mean value of the orientation angle between two runs of the helical propulsion system. However, the propeller can achieve reorientation using successive run-and-reverse, as is seen in some bacteria. For example, Pseudoalteromonas haloplanktis and Shewanella putrefaciens, each with a single polar flagellum, use a run-and-reverse strategy [206, 207]. Reversal of the flagellum motor reverses the swimming direction by $180^{\circ}$; however deviations from this pure reversal enable the microorganism to swim in new directions. This strategy could also be adopted by artificial microswimmers where iterating the run-and-reverse pattern can provide variations in the swimming direction. Devising a microrobotic system with an appropriate control or a self-regulated learning strategy will result in a reliable steering methodology.

\subsection{Swimming on a helical path}

Microrobots have been propelled using non-biomimetic methods that can be achieved through the application of magnetic fields. The gradients of a non-uniform magnetic field apply forces on a magnetized body [208-210]. Such gradient direct pulling has been realized using electromagnetic actuation systems, which have no analog in nature. However, we 
Fig. 9 a Run and tumbling suggested for a microrobot that consists of a rigid helix and several flexible filaments. The microrobot is propelled forward by rotation of the helical flagellum. However, when the rotational torque is removed, the flexible filaments fly apart, and the microrobot tumbles and changes its orientation. b The helical propeller is connected to the body with a flexible hook to provide the ability to flick the propeller. c Two rigid helices connected through a flexible hook. d Application of magnetic force $\left(F_{\mathrm{m}}\right)$ and magnetic torque $\left(T_{\mathrm{m}}\right)$ on a magnetic microrobot steers the microrobot in a helical trajectory when the force and torque are not parallel or perpendicular. The direction of the helical path, hence the microrobot, can be controlled by the frequency of magnetic torque.

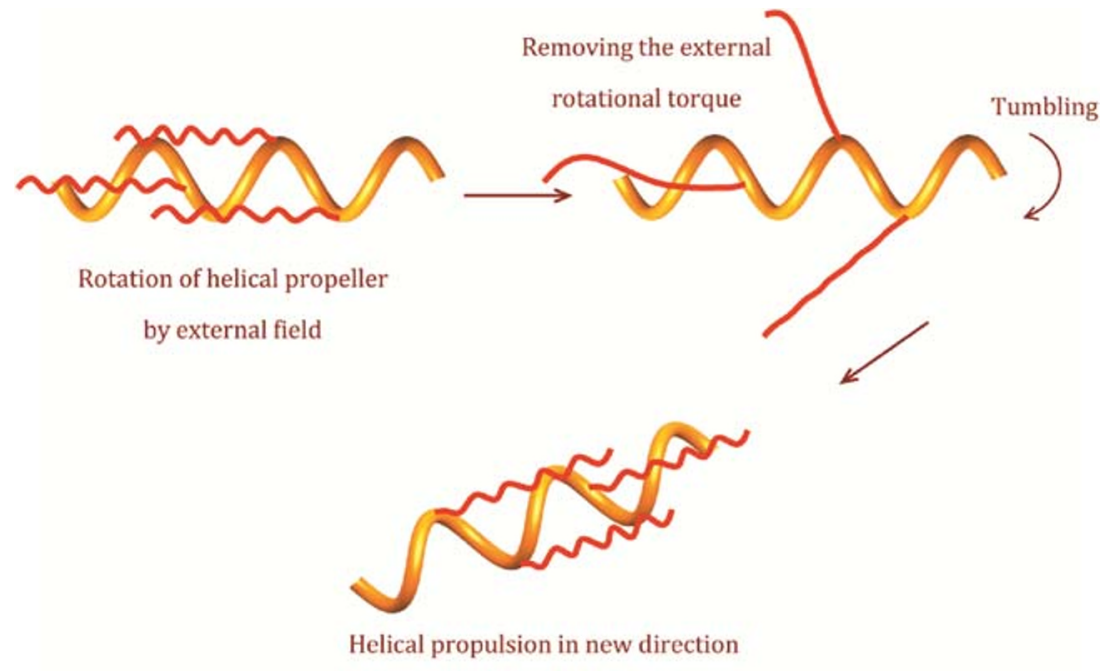

(a)

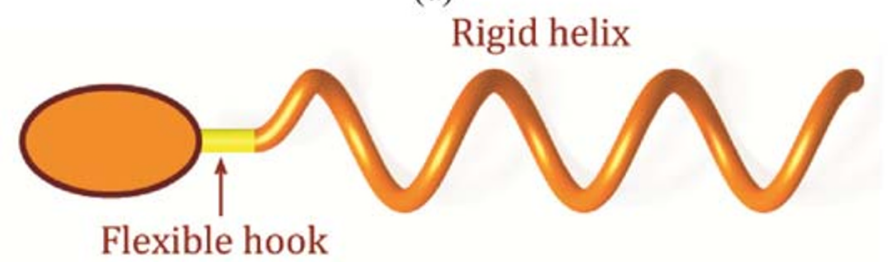

(b)

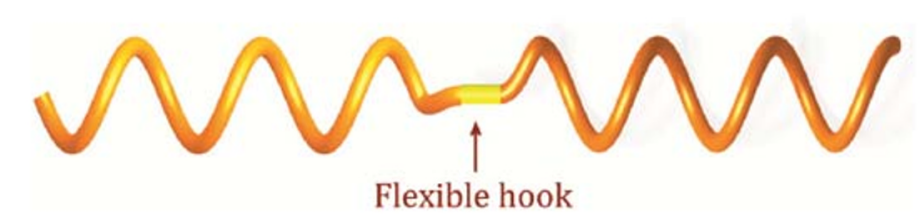

(c)

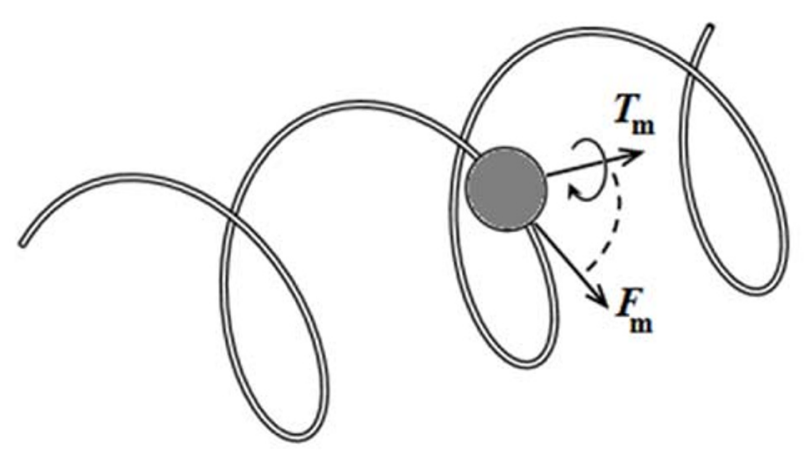

(d) may adopt a biomimetic methodology for direction control in such magnetic microrobots. Kim et al. showed that a rolling motion along with direct pulling increases the speed of a microrobot [211]. Tung et al. proposed the non-contact transportation of micro-objects using a rolling motion of a magnetic microrobot [212]. In addition to the advantages of rolling motion, we consider its potential for direction control in magnetic microrobots.

Gradient pulling of a magnetic microrobot can occur along with the application of a rotating magnetic field, as depicted in Fig. 9d. The motion of the object can now be described using its linear and angular velocities. When the linear and angular 
velocities are not parallel or perpendicular, the microrobot swims along a helical path. The net microrobot swimming direction is along the central axis of the helical path. Furthermore, with increased swimming speed, helical-path swimming opens up possibilities for direction control of a gradient-pulled microrobot. As described for microorganisms in section 3.3, the direction of a microrobot can be controlled by changes in its rotational velocity.

Abbott et al. showed that the magnetic gradient of a set of electromagnetic coils decays with a fourth order of the length over which it is projected, while a magnetic field decays with the third order [213]. Thus, there are more restrictions on the magnitude of electromagnetic gradients than magnetic fields. These restrictions make reorientation and control more challenging. Using helical-path swimming may contribute to the controllability of microrobots because the direction is controlled by the rotational velocity of the magnetic field.

\subsection{Speed modulation}

Direction change in a microrobot with several helical flagella may be realized using speed modulation. An individual rotary motor drives each flagellum. When the motors are rotated with identical frequencies, the microrobot swims along a linear path. However, changes in the rotational frequency of each flagellum will result in the reorientation of the microrobot. Redirection can be achieved by magnitude differentiation between flagella frequencies, or by a change in the clockwise/ counterclockwise rotation of the flagella. At least three flagella with individual rotary motors are required for a $6-\mathrm{DOF}$ motion in a microrobot.

Using the wireless application of a rotational magnetic field, current helical propellers are driven at different motion modes depending on the field frequency $[172,214]$. The magnetic field, at certain revolutions, synchronizes the rotation of all flagella of the microrobot with its velocity. For this type of actuation, one can use different design parameters of flagella to generate speed differentiation. However, this differentiation will be fixed and will not provide the required maneuverability. Although fabrication of a rotary motor, similar to molecular motors of bacterial flagella, is currently challenging, rapid advances in micro/nanofabrication may yield such a system in the not-too-distant future. Then, speed modulation would likely be the easiest method to create a stand-alone maneuverable microrobot.

\subsection{Artificial flagella with complex geometry}

Helical flagella that have been realized to date have smooth and simple structures. However, helical propellers with complex structures may show different swimming behaviors. A turbulent flow can be generated at the surface of helices with grooves and ridges, as seen in some microorganisms. This local turbulence affects the hydrodynamic balance and leads to changes in the orientation of a microrobot. Turbulence, at the surface, depends on the geometry and rotational frequency of the flagella. A threshold frequency can be specified for a given structure of flagella, beyond which the flow becomes turbulent. As long as the frequency is below this threshold value, the microrobot moves forward along a linear path. However, increasing the frequency over the threshold will result in a direction change of the microswimmer.

Complex structures of flagella can be achieved using threedimensional laser lithography [215], which has been recently used to fabricate helical microswimmers (Fig. 10a,b) [169] and bio-scaffolds $[211,216]$. This technique enables the fabrication of 3D structures with desired geometry at a high resolution. Two laser beams form a single ellipsoidal spot, a tool for scanning the pre-defined 3D structure within a photoresist (Fig. 10c). Parts of the photoresist exposed by the laser beam are polymerized, and the 3D structure can be produced by removing the unexposed photoresist in a developer.

\subsection{Flagella with mastigonemes}

For a helical flagellum bearing mastigonemes, the tangential drag force outweighs the normal drag force. Thus, the microrobot moves in the direction of helical wave propagation. This is unlike the case with smooth helical propellers, which cause motion in the reverse direction. Tottori and Nelson showed that a helical propeller bearing orthogonal appendages (with respect to the helix) swims in the reverse direction than would be expected for a helical propeller without mastigonemes [217]. They demonstrated that the swimming direction and velocity are determined by the length and spacing ratio of the mastigonemes. Fig. 10d shows the helical structures bearing mastigonemes with various length-tospacing ratios fabricated using 3D laser lithography. The $180^{\circ}$ change in swimming direction occurs when the protruding appendages on the helix surface are passive, rigid, and orthogonal. Although the mastigonemes of Ochromonas have also been reported as relatively rigid filaments, they can also bend, up to an extent, during hydrodynamic interaction with the fluid at their intersection with the main flagellum. The question is how the flexiblity of mastigonemes affect their performance in changing the swimming direction? Researchers have modeled the hydrodynamics of the flagellate with mastigonemes and concluded that increasing the flexibility will decrease the efficiency of reverse swimming $[156,158]$. Brennen specified a range for the rigidity of actual mastegonemes [156].

The real mastigonemes are passive [156], however, artificial filaments with an active control that provide the required flexibility would enable a helical microrobot to use the ciliary effect of mastigonemes to tune its orientation. How much mastigonemes shift the ratio between tangential and normal 
Fig. 10 a An array of helical structures, and $\mathbf{b}$ A vertical helical microswimmer, fabricated using 3D laser lithography [169]. c The 3-step process of 3D laser lithography, which includes photoresist coating, laser exposure, and development. d Helical structures bearing perpendicular mastigonemes, with various length-to-spacing ratios, fabricated using 3D laser lithography and coated by magnetic material. The scale bar is $10 \mu \mathrm{m}$ [217].
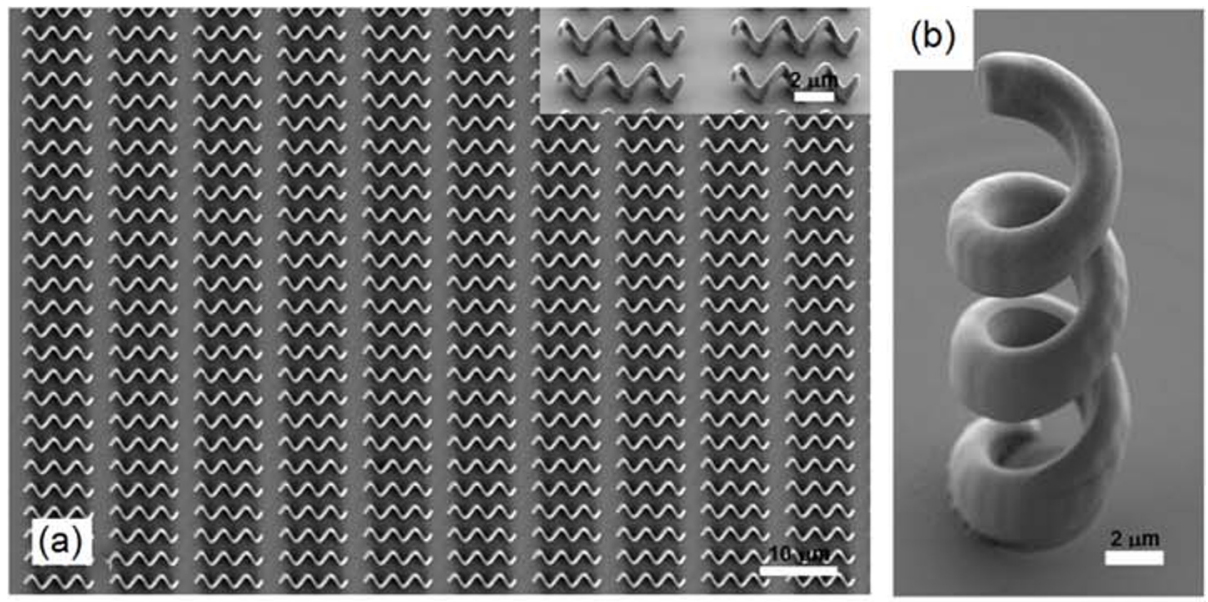

(c)

\section{photoresist}

glass substrate

1) Photoresist coating

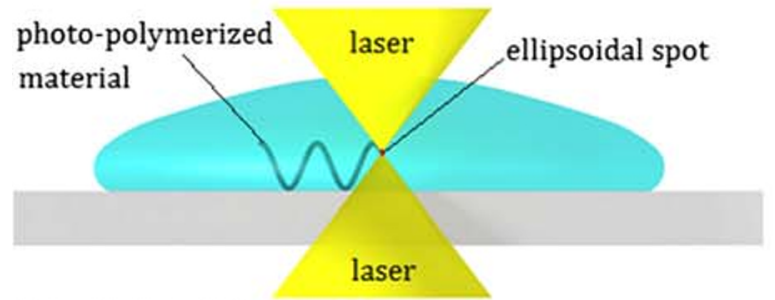

2) Laser exposure

3D structure

W

3) Development

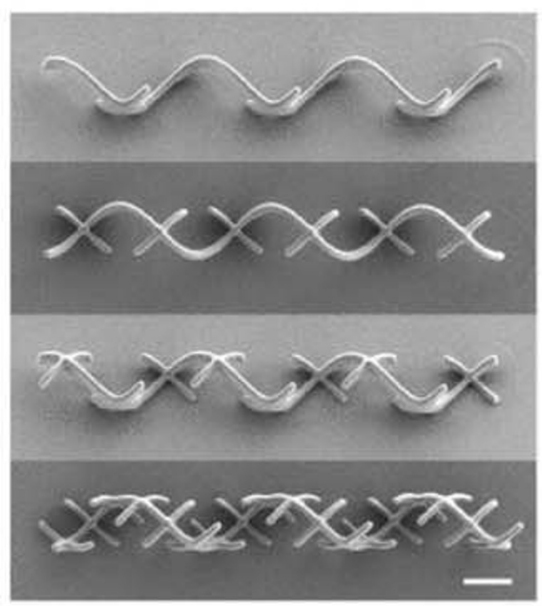

(d) 


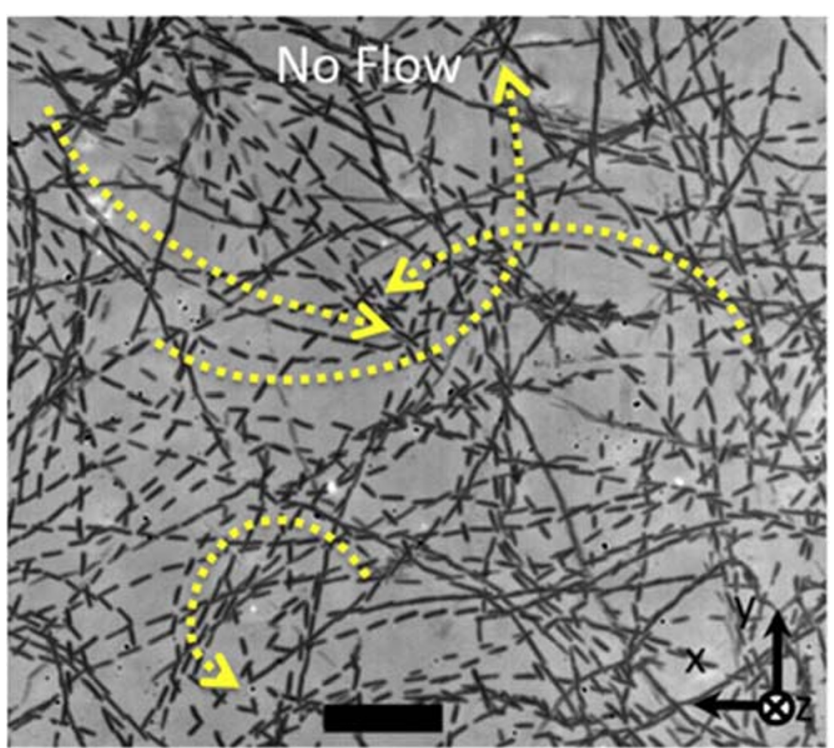

Fig. 11 E. coli swims in circular trajectories near a solid boundary when there is no external fluid flow. The images are taken at $30 \mathrm{~Hz}$ and shown for every fifth sequential frame [226].

drag coefficients regulates the reorientation of the helical propeller. On the other hand, flexible passive mastigonemes may help the helical microrobot in redirection using tumbling.

\section{Direction change due to the wall effect}

The interaction between microorganism cells and their propulsion systems with solid surface results in different swimming behaviors of cells. Sperms are captured by a hydrodynamic trap at surfaces [218-222]. They tend to swim in circular or curvilinear trajectories instead of along helical paths. The helical swimming path of the sperm changes to a circular path near a surface due to the combination of hydrodynamic repulsion of the wall and sperm velocity [223]. This non-random effect enables sperms to fulfill their role in fertilization [222]. Prokaryotic microorganisms, such as E. coli, also tend to accumulate near surfaces, where they switch from a straight run and tumble to a circular motion $[110,224,225]$. The swimming trajectories of $E$. coli near a solid surface are shown in Fig. 11. The microorganism swims in circular paths when there is no external stimulation (such as a fluid flow) [226]. Lauga et al. modeled the motion of E. coli near solid boundaries [227]. They showed that the tendency of bacteria to swim into the solid boundary is due to force- and torque-free swimming. The wall effect has also been reported for monotrichous flagellates $[109,110]$ and ciliated microorganisms [228, 229].

The wall effect also depends on pusher or puller type, another categorization of swimmers [230]. A pusher is a swimmer that exerts fluid to the back away from the body, while a puller generates a flow towards the body [231]. While moving parallel to the wall, a pusher type swimmer is attracted to it, whereas a puller type microorganism is repelled. Different hydrodynamic interactions of the puller and pusher type with the wall also cause the swimmer to reorient in opposite directions [232].

The wall effect is also present for artificial microswimmers when they change direction. Zhang et al. reported that an artificial bacterial propeller tends to drift towards a wall while swimming in its neighborhood [168]. However, the body and flagellum of an artificial microswimmer are not hinged together and do not counter-rotate to produce a circular trajectory, as seen in real bacteria [233]. The wall effect might be undesirable and should be compensated for within the microrobotic control in some applications. However, it may also provide the possibility of direction control for artificial microswimmers. For example, these hydrodynamic interactions of a microrobot with a wall can keep it close to a wall, so that the microrobot follows the wall trajectory.

\section{Summary and Outlook}

Propulsion methodologies of microorganisms have been studied in several reviews; however, to our knowledge, no previous review has investigated the strategies of microorganisms for direction control. Although not exhaustive, section 3

Table 1. Reorientation strategies and mechanisms of swimming microorganisms

\begin{tabular}{|c|c|c|}
\hline Reorientation strategy & Microorganism type & Reorientation mechanism \\
\hline Tumbling & Peritrichous flagellates (Multi-flagella) & Flagella rotation reversal \\
\hline Reverse and flick & Monotrichous flagellates (single-flagellum) & Flick in the flagellum hook due to a buckling instability \\
\hline Helical-path swimming & $\begin{array}{l}\text { Eukaryotic flagellates } \\
\text { Ciliates Sperms }\end{array}$ & Varying rotational velocity of the cell's body \\
\hline Speed modulation & $\begin{array}{l}\text { Monotrichous or peritrichous flagellates } \\
\text { (unidirectional flagella rotation) }\end{array}$ & $\begin{array}{l}\text { Acceleration or deceleration of the flagella rotational } \\
\text { velocity }\end{array}$ \\
\hline Complex flagella & Peritrichous flagellates & $\begin{array}{l}\text { Breaking the hydrodynamic integrity of the flagella } \\
\text { bundle in rotation }\end{array}$ \\
\hline Mastigonemes & Flagellates & $\begin{array}{l}\text { Change in the tangential drag coefficient of flagella } \\
\text { bearing mastigonemes }\end{array}$ \\
\hline
\end{tabular}


provides the major methodologies that microorganisms use for reorientation. Tumbling of peritrichous $E$. coli, due to the reversal of rotation in its flagella; the backtrack motion of the monotrichous $V$. alginolyticus, when it is followed by a flagellum flick; control of rotational velocity by sperms that swim along a helical path; speed modulation of the flagellum in $R$. sphaeroides, using turbulent flow at the flagella surface in $R$. lupini; and the effect of mastigonemes in Ochromonas malhamensis illustrate a variety of strategies for reorientation in microorganisms. These strategies along with the main physical mechanism behind them are outlined in Table 1. The trajectory of microorganisms can also be altered by the impact of a solid boundary, where they mostly swim along a circular path.

For engineers, microorganisms have been a source of inspiration for propulsion at the micro- and nanoscale. These autonomous micro-/nanorobots have attracted much research attention because of their application in biomedical areas [195, 197, 234]. Drug delivery at the cell level, in vivo surgery, and cell delivery to the internal tissues of the human body would be promising applications of these micro-/nanodevices. To perform these risky operations, the micro-/nanorobots need to reorient and control their trajectories to follow the complex geometries of their environments. Thus, looking at the strategies of their natural counterparts may inspire control mechanisms for these artificial swimmers. This knowledge can also help to control the microorganisms for cargo (drug/cell) transport and delivery in biomedical applications.

We have surveyed the reorientation mechanisms of microorganisms and proposed ideas to mimic them in artificial micro-/nanoswimmers. Reversal of the flagella of a robot with several flagella rotating individually or perturbations of

Table 2. Material characteristics of a number of flagella-based microrobots

\begin{tabular}{|c|c|c|c|c|c|}
\hline Structure & Size & Material & Fabrication method & $\begin{array}{l}\text { Young's } \\
\text { Modulus }\end{array}$ & Reference \\
\hline Helical & $\begin{array}{l}\text { Length: } 2 \mu \mathrm{m} \\
\text { Dia: } 200 \mathrm{~nm}\end{array}$ & $\mathrm{SiO} 2$ & $\begin{array}{l}\text { Glancing } \\
\text { angle deposition }\end{array}$ & $\sim 70 \mathrm{GPa}$ & $\begin{array}{l}\text { Ghosh and } \\
\text { Fischer } 2009 \text { [166] }\end{array}$ \\
\hline Helical & $\begin{array}{l}\text { Length: } 30-100 \mu \mathrm{m} \\
\text { Dia: } 2.8 \mu \mathrm{m}\end{array}$ & InGaAs/GaAs bilayers & $\begin{array}{l}\text { Microfabrication techniques } \\
\text { such as photolithography, } \\
\text { resistive ion etching (RIE), } \\
\text { evaporation, etc. }\end{array}$ & $\sim 80 \mathrm{GPa}$ & Bell et al. 2007 [241] \\
\hline Helical & $\begin{array}{l}\text { Length: } 4-65 \mu \mathrm{m} \\
\text { Dia: } 1-10 \mu \mathrm{m}\end{array}$ & SU-8, IP-L & 3D direct laser writing (DLW) & $\begin{array}{l}\text { SU-8: } 2-4 \mathrm{GPa} \\
\text { IP-L: } 1-2 \mathrm{GPa}\end{array}$ & Tottori et al. 2012 [169] \\
\hline Helical & $\begin{array}{l}\text { Length: } 15.7 \mu \mathrm{m} \\
\text { Dia: } 5.3 \mu \mathrm{m}\end{array}$ & $\begin{array}{l}\text { Gel resist composed of } \\
\text { inorganic-(Si-O-Si)-organic } \\
\text { groups, commercially known } \\
\text { as ORMOCOMP }\end{array}$ & 3D direct laser writing (DLW) & $\sim 1 \mathrm{GPa}$ & Qiu et al. 2014 [171] \\
\hline Helical & $\begin{array}{l}\text { Length: } 14-28 \mu \mathrm{m} \\
\text { Dia: } 1.5-3 \mu \mathrm{m}\end{array}$ & $\begin{array}{l}\text { Superparamagnetic hydrogel } \\
\text { composed } \\
\text { of poly (ethylene } \\
\text { glycol) diacrylate (PEG-DA), } \\
\text { and pentaerythritol } \\
\text { triacrylate (PE-TA) }\end{array}$ & 3D direct laser writing (DLW) & $\sim 100 \mathrm{kPa}$ & Peters et al. 2016 [176] \\
\hline Planar flexible tail & $\begin{array}{l}\text { Length: } 8.8 \mu \mathrm{m} \\
\text { Thickness: } 0.6 \mu \mathrm{m}\end{array}$ & Polypyrrole (PPy) & Multistep electrodeposition & $0.1 \mathrm{GPa}$ & Ahmed et al. 2016 [188] \\
\hline $\begin{array}{l}\text { Helical tail, Spiral } \\
\text { tail, Planar } \\
\text { flexible tail }\end{array}$ & $\begin{array}{l}\text { Length: } 750 \mu \mathrm{m} \\
\text { Thickness: } 50 * 30 \mu \mathrm{m}\end{array}$ & $\begin{array}{l}\text { N-isopropylacrylamide } \\
\text { (NIPAAm)/poly (ethylene glycol) } \\
\text { diacrylate (PEGDA) }\end{array}$ & $\begin{array}{l}\text { Sequential photolithography } \\
\text { patterning }\end{array}$ & $11.4 \mathrm{kPa}$ & Huang et al. 2016 [202] \\
\hline Helical & $\begin{array}{l}\text { Length: } 20 \mu \mathrm{m} \\
\text { Dia: } 0.65 \mu \mathrm{m}\end{array}$ & Polypyrrole (PPy) & $\begin{array}{l}\text { Template-assisted } \\
\text { electrodeposition }\end{array}$ & $0.1 \mathrm{GPa}$ & Zeeshan et al. 2014 [242] \\
\hline Helical & $\begin{array}{l}\text { Length: } 600 \mathrm{~nm}-3 \mu \mathrm{m} \\
\text { Dia: } 100-400 \mathrm{~nm}\end{array}$ & Palladium (Pd) & $\begin{array}{l}\text { Template-assisted } \\
\text { electrodeposition }\end{array}$ & $\sim 120 \mathrm{GPa}$ & Li et al. 2014 [243] \\
\hline Planar flexible body & $\begin{array}{l}\text { Length: } 1000 \mu \mathrm{m} \\
\text { Dia: } 200 \mu \mathrm{m}\end{array}$ & Liquid-crystal elastomer & $\begin{array}{l}\text { UV curing of the } \\
\text { manually-pulled fiber }\end{array}$ & $\sim 1000 \mathrm{kPa}$ & Palagi er al. 2016 [244] \\
\hline Helical (ribbon) & $\begin{array}{l}\text { Length: } 80 \mu \mathrm{m} \\
\text { Width: } 5 \mu \mathrm{m} \\
\text { Thickness: } 1 \mu \mathrm{m}\end{array}$ & $\begin{array}{l}\text { Poly(N-isopropylacrylamide) } \\
\text { (PNIPAm) microgel with } \\
\text { embedded gold nanorods }\end{array}$ & Molding & $\sim 90-465 \mathrm{kPa}$ & Mourran et al. 2017 [181] \\
\hline Helical & $\begin{array}{l}\text { Length: } 120 \mu \mathrm{m} \\
\text { Dia: } 40 \mu \mathrm{m}\end{array}$ & $\begin{array}{l}\text { Superparamagnetic hydrogel } \\
\text { composed of } \\
\text { PEGDA-pentaerythritol } \\
\text { triacrylate (PETA), Fe3O4 MNPs, } \\
\text { and 5-fluorouracil (5-FU) }\end{array}$ & $\begin{array}{l}\text { 3D direct laser } \\
\text { writing (DLW) }\end{array}$ & $\sim 1000 \mathrm{kPa}$ & Park et al. 2019 [245] \\
\hline Helical & $\begin{array}{l}\text { Length: } 20 \mu \mathrm{m} \\
\text { Dia: } 6 \mu \mathrm{m}\end{array}$ & $\begin{array}{l}\text { Composite hydrogel containing } \\
\text { gelatin methacryloyl, } \\
\text { photoinitiator, } \\
\text { and iron oxide nanoparticles }\end{array}$ & $\begin{array}{l}\text { 3D direct laser } \\
\text { writing (DLW) }\end{array}$ & $\sim 100 \mathrm{kPa}$ & Ceylan et al. 2019 [180] \\
\hline
\end{tabular}


flexible appendages in helical motion can cause tumbling for a swimmer. Another strategy is to devise a rigid helical flagellum with a flexible hook to provide a tool for flicking the flagellum, changing the robot's direction. Another approach is to use magnetic micro-/nanorobots that are driven by simultaneous torque and force. They travel along a helical path, the direction of which can be controlled by the rotational velocity of the applied field. We can also use speed differentiation between several flagella that propel a micro-/nanorobot to reorient its swimming trajectory. Complex structures of flagella can be shaped using 3D micro-/nanofabrication technologies $[169,178]$. Flagella with complex shapes may establish turbulence at the flagella surface, and such turbulence can cause the swimmer to change direction. The reverse direction has already been shown for a helix with mastigonemes [217]; use and control of active mastigonemes could provide the required tool for micro-/nanoswimmer maneuverability.

In summary, the field of micro-/nanorobotics is a multidisciplinary research area. Among several areas, fabrication is of great importance. Fabrication of micro- or nanomotors with varying rotational speeds that could be driven wirelessly would be promising for the realization of autonomous micro-/ nanoswimmers with high maneuverability. Table 2 summarizes the material properties and fabrication method for a number of developed flagella-based microrobots. The data reveals a growing interest towards the soft micro-/nanorobotics [235-237]. Reliable fabrication of sufficiently flexible materials such as hydrogels [176, 202, 238, 239] may also provide the required tools for the reorientation and control of swimming micro-/nanorobots.

Acknowledgements The author would like to thank Prof. Bradley Nelson (ETH Zurich) and Prof. Hongsoo Choi (Daegu Gyeongbuk Institute of Science and Technology) for valuable discussions.

Open Access This article is licensed under a Creative Commons Attribution 4.0 International License, which permits use, sharing, adaptation, distribution and reproduction in any medium or format, as long as you give appropriate credit to the original author(s) and the source, provide a link to the Creative Commons licence, and indicate if changes were made. The images or other third party material in this article are included in the article's Creative Commons licence, unless indicated otherwise in a credit line to the material. If material is not included in the article's Creative Commons licence and your intended use is not permitted by statutory regulation or exceeds the permitted use, you will need to obtain permission directly from the copyright holder. To view a copy of this licence, visit http://creativecommons.org/licenses/by/4.0/.

\section{References}

1. Costello EK, Lauber CL, Hamady M, Fierer N, Gordon JI, Knight R (2009) Bacterial community variation in human body habitats across space and time. Science 326(5960):1694-1967

2. Fenchel T (1987) Ecology of protozoa: the biology of free-living phagotrophic protists. Springer-Verlag, Berlin
3. DeLong E. F (1992) Archaea in coastal marine environmentsProc. Natl. Acad. Sci. 89(12):5685-5689

4. Van den Hoek C (1995) Algae: an introduction to phycology. Cambridge University Press, Cambridge

5. Vogel S (1996) Life in moving fluids: the physical biology of flow. Princeton University Press, Princeton

6. Sfakiotakis M, Lane DM, Davies JBC (1999) Review of fish swimming modes for aquatic locomotion. IEEE J. Oceanic Eng. 24(2):237-252

7. Dusenbery DB (2011) Living at micro scale: the unexpected physics of being small. Harvard University Press, Cambridge

8. Purcell E (1977) Life at low reynolds number. Am. J. Phys. 45(1): 3-11

9. Vogel S (2008) Modes and scaling in aquatic locomotion. Integr. Comp. Biol. 48(6):702-712

10. Jahn TL, Bovee EC (1965) Movement and locomotion of microorganisms. Annu. Rev. Microbiol. 19:21-58

11. Yates GT (1986) How microorganisms move through water: the hydrodynamics of ciliary and flagellar propulsion reveal how microorganisms overcome the extreme effect of the viscosity of water. Am. Sci. 74(4):358-365

12. Gray J (1955) The movement of sea-urchin spermatozoa. J. Exp. Biol. 32:775-801

13. Gray J, Hancock G (1955) The propulsion of sea-urchin spermatozoa. J. Exp. Biol. 32:802-814

14. Gillies EA, Cannon RM, Green RB, Pacey AA (2009) Hydrodynamic propulsion of human sperm. J. Fluid Mech. 625: 445-474

15. Werner M, Simmons LW (2008) Insect sperm motility. Biol. Rev. 83(2):191-208

16. Berg HC (2004) E. coli. In: Motion. Springer-Verlag, New York

17. Brennen C, Winet H (1977) Fluid mechanics of propulsion by cilia and flagella. Annu. Rev. Fluid Mech. 9:339-398

18. Jahn TL, Votta JJ (1972) Locomotion of protozoa. Annu. Rev. Fluid Mech. 4:93-116

19. Pak OS, Spagnolie SE, Lauga E (2012) Hydrodynamics of the double-wave structure of insect spermatozoa flagella. J. R. Soc. Interface 9(73):1908-1924

20. Taylor G (1951) Analysis of the swimming of microscopic organisms. Proc. R. Soc. London, Ser. A 209(1099):447-461

21. Hillier J (1950) Electron microscopy of microorganisms and viruses. Annu. Rev. Microbiol. 4(1):1-20

22. Collins SP, Pope RK, Scheetz RW, Ray RI, Wagner PA, Little BJ (1993) Advantages of environmental scanning electron microscopy in studies of microorganisms. Microsc. Res. Tech. 25(5-6): 398-405

23. Happel J, Brenner H (1965) Low Reynolds number hydrodynamics: with special applications to particulate media. Prentice-Hall, Inc., Englewood Cliffs

24. Lighthill J (1975) Mathematical Biofluiddynamics. SIAM, Philadelphia

25. Lighthill J (1976) Flagellar hydrodynamics. SIAM Rev. 18(2): $161-230$

26. Blum JJ, Hines M (1979) Biophysics of flagellar motility. Q. Rev. Biophys 12(2):103-180

27. Childress S (1981) Mechanics of swimming and flying. Cambridge University Press, Cambridge

28. Kim S, Karrila SJ (1991) Microhydrodynamics: principles and selected applications. Butterworth-Heinemann, Boston

29. Lauga E, Powers TR (2009) The hydrodynamics of swimming microorganisms. Rep. Prog. Phys. 72(9):096601

30. Rohan F, Zuniga M, Sassine FR, Karakoy M, Gracias DH (2011) Enabling cargo-carrying bacteria via surface attachment and triggered release. Small 7(5):588-592

31. Akin D, Sturgis J, Ragheb K, Sherman D, Burkholder K, Robinson JP, Bhunia AK, Mohammed S, Bashir R (2007) 
Bacteria-mediated delivery of nanoparticles and cargo into cancer cells. Nat. Nanotechnol. 2(7):441-449

32. Park BW, Zhuang J, Yasa O, Sitti M (2017) Multifunctional bacteria-driven microswimmers for targeted active drug delivery. ACS Nano 11(9):8910-8923

33. Stanton MM, Park BW, Vilela D, Bente K, Faivre D, Sitti M, Sánchez S (2017) Magnetotactic bacteria powered biohybrids target $E$. coli biofilms. ACS Nano 11(10):9968-9978

34. Ricotti L, Trimmer B, Feinberg AW, Raman R, Parker KK, Bashir R, Sitti M, Martel S, Dario P, Menciassi A (2017) Biohybrid actuators for robotics: A review of devices actuated by living cells. Sci. Robot 2(12):eaaq0495

35. Zhuang J, Park BW, Sitti M (2017) Propulsion and chemotaxis in bacteria-driven microswimmers. Adv. Sci. 4(9):1700109

36. Guasto JS, Rusconi R, Stocker R (2012) Fluid mechanics of planktonic microorganisms. Annu. Rev. Fluid Mech. 44(1):373400

37. Swan JW, Brady JF, Moore RS (2011) Modeling hydrodynamic self-propulsion with stokesian dynamics. Or teaching stokesian dynamics to swim. Phys. Fluids 23(7):071901

38. de la Torre JG, Bloomfield VA (1977) Hydrodynamic theory of swimming of flagellated microorganism. Biophys. J. 20(1):49-67

39. Rodenborn B, Chen CH, Swinney HL, Liu B, Zhang HP (2013) Propulsion of microorganisms by a helical flagellum. Proc. Natl. Acad. Sci 110(5):E338-E347

40. Scharf B (2002) Real-time imaging of fluorescent flagellar filaments of Rhizobium lupini H13-3: flagellar rotation and $\mathrm{pH}-$ induced polymorphic transitions. J. Bacteriol. 184(21):5979-5986

41. Lederberg J (1987) Genetic recombination in bacteria: A discovery account. Annu. Rev. Genet. 21:23-46

42. Aizawa SI (1996) Flagellar assembly in Salmonella typhimurium. Mol. Microbiol. 19(1):1-5

43. Berg H, Anderson R (1973) Bacteria swim by rotating their flagellar filaments. Nature 245(5425):380-382

44. Khan S, Scholey JM (2018) Assembly, functions and evolution of archaella, flagella and cilia. Curr. Biol. 28(6):R278-R292

45. Trachtenberg S, Hammel I (1992) The rigidity of bacterial flagellar filaments and its relation to filament polymorphism. J. Struct. Biol. 109(1):18-27

46. Namba K, Vonderviszt F (1997) Molecular architecture of bacterial flagellum. Q. Rev. Biophys. 30(1):1-65

47. Berg HC (2002) The rotary motor of bacterial flagella. Annu. Rev. Biochem. 72:19-24

48. Berg HC (2000) Motile behavior of bacteria. Phys. Today 53(1): 24-29

49. van Albada SB, Tanase-Nicola S, ten Wolde PR (2009) The switching dynamics of the bacterial flagellar motor. Mol. Syst. Biol. 5:316

50. Sleigh M (1991) Mechanisms of flagellar propulsion. Protoplasma 164(1):45-53

51. Lowe G, Meister M, Berg HC (1987) Rapid rotation of flagellar bundles in swimming bacteria. Nature 325:637-640

52. Berg HC (2008) Bacterial flagellar motor. Curr. Biol. 18(16): R689-R691

53. Brokaw C (1965) Non-sinusoidal bending waves of sperm flagella. J. Exp. Biol. 43(1):155-169

54. Wan KY, Leptos KC, Goldstein RE (2014) Lag, lock, sync, slip: the many 'phases' of coupled flagella. J. R. Soc. Interface 11(94): 20131160

55. Alexander RM (1979) The invertebrates. Cambridge University Press, New York

56. Blake JR, Sleigh MA (1974) Mechanics of ciliary locomotion. Biol. Rev. 49(1):85-125

57. Blake J (1973) A finite model for ciliated micro-organisms. J. Biomechanics. 6(2):133-140
58. Machemer H (1972) Ciliary activity and the origin of metachrony in Paramecium: effects of increased viscosity. J. Exp. Biol. 57(1): 239-259

59. Sanderson M, Sleigh M (1981) Ciliary activity of cultured rabbit tracheal epithelium: beat pattern and metachrony. J. Cell Sci. 47: 331-347

60. Gueron S, Levit-Gurevich K, Liron N, Blum JJ (1997) Cilia internal mechanism and metachronal coordination as the result of hydrodynamical coupling. Proc. Natl. Acad. Sci. 94(12):6001-6006

61. Feinleib ME (1975) Phototactic response of Chlamydomonas to flashes of light-I. response of cell populations. Photochem. Photobiol. 21(5):351-354

62. Boscov JS, Feinleib ME (1979) Phototactic response of Chlamydomonas to flashes of light-II. response of individual cells Photochem. Photobiol. 30:499-505

63. Mitchell DR (2000) Chlamydomonas flagella. J. Phycol. 36:261273

64. Berg HC, Brown DA (1972) Chemotaxis in Escherichia coli analysed by three-dimensional tracking. Nature 239(5374):500 504

65. Adler J (1973) A method for measuring chemotaxis and use of the method to determine optimum conditions for chemotaxis by Escherichia coli. J. Gen. Microbiol. 74(1):77-91

66. Brown DA, Berg HC (1974) Temporal stimulation of chemotaxis in Escherichia coli. Proc. Natl. Acad. Sci. 71(4):1388-1392

67. Blair DF (1995) How bacteria sense and swim? Annu. Rev. Microbiol. 49:489-522

68. Zonia L, Bray D (2009) Swimming patterns and dynamics of simulated Escherichia coli bacteria. J. R. Soc. Interface 6(40): 1035-1046

69. Diehn B, Feinleib M, Haupt W, Hildebrand E, Lenci F, Nultsch W (1977) Terminology of behavioral responses of motile microorganisms. Photochem. Photobiol. 26(6):559-560

70. Krell T, Lacal J, Munoz-Martinez F, Reyes-Darias JA, Cadirci BH, Garcia-Fontana C, Ramos JL (2011) Diversity at its best: bacterial taxis. Environ. Microbiol. 13(5):1115-1124

71. Marangoni R, Preosti G, Colombetti G (2000) Phototactic orientation mechanism in the ciliate Fabrea salina, as inferred from numerical simulations. J. Photochem. Photobiol., B 54(2-3):185193

72. Weibel DB, Garstecki P, Ryan D, DiLuzio WR, Mayer M, Seto JE, Whitesides GM (2005) Microoxen: Microorganisms to move microscale loads. PNAS 102(34):11963-11967

73. Berg HC (1975) Chemotaxis in bacteria. Annu. Rev. Biophys. Bioeng. 4(00):119-136

74. Wadhams GH, Armitage JP (2004) Making sense of it all: bacterial chemotaxis. Nat. Rev. Mol. Cell Biol. 5(12):1024-1037

75. Alexandre G, Greer-Phillips S, Zhulin IB (2004) Ecological role of energy taxis in microorganisms. FEMS Microbiol. Rev. 28(1): $113-126$

76. Taylor BL, Zhulin IB, Johnson MS (1999) Aerotaxis and other energy-sensing behavior in bacteria. Annu. Rev. Microbiol. 53(1): 103-128

77. Bastos-Arrieta J, Revilla-Guarinos A, Uspal WE, Simmchen J (2018) Bacterial biohybrid microswimmers. Frontiers in Robotics and AI 5:1

78. Paulick A, Jakovljevic V, Zhang SM, Erickstad M, Groisman A, Meir Y, Ryu WS, Wingreen NS, Sourjik V (2017) Mechanism of bidirectional thermotaxis in Escherichia coli. eLife 6:e26607

79. Klumpp S, Faivre D (2016) Magnetotactic bacteria. Eur. Phys. J. Special Topics 225:2173-2188

80. Lefevre CT, Bennet M, Landau L, Vach P, Pignol D, Bazylinski DA, Frankel RB, Klumpp S, Faivre D (2014) Diversity of magneto-aerotactic behaviors and oxygen sensing mechanisms in cultured magnetotactic bacteria. Biophys. J. 107(2):527-538 
81. Marcos FHC, Powers TR, Stocker R (2012) Bacterial rheotaxis. PNAS 109(13):4780-4785

82. Palacci J, Sacanna S, Abramian A, Barral J, Hanson K, Grosberg AY, Pine DJ, Chaikin PM (2015) Artificial rheotaxis. Sci. Adv. 1(4):e1400214

83. Packer HL, Armitage JP (1994) The chemokinetic and chemotactic behavior of Rhodobacter sphaeroides: two independent responses. J. Bacteriol. 176(1):206-212

84. Zhulin I, Armitage JP (1993) Motility, chemokinesis, and methylation-independent chemotaxis in Azospirillum brasilense. J. Bacteriol. 175(4):952-958

85. Ping L (2010) The asymmetric flagellar distribution and motility of Escherichia coli. J. Mol. Biol. 397(4):906-916

86. Leifson E (1951) Staining, shape, and arrangement of bacterial flagella. J. Bacteriol. 62(4):377-389

87. Leifson E, Hugh R (1953) Variation in shape and arrangement of bacterial flagella. J. Bacteriol. 65(3):263-271

88. Leifson E (1960) Atlas of bacterial flagellation. Academic Press, New York and London

89. Macnab RM, Ornston MK (1977) Normal-to-curly flagellar transitions and their role in bacterial tumbling. Stabilization of an alternative quaternary structure by mechanical force. J. Mol. Biol. 112(1):1-30

90. Machin K (1963) The control and synchronization of flagellar movement. Proc. R. Soc. London, Ser. B 158(970):88-104

91. Macnab RM (1977) Bacterial flagella rotating in bundles: a study in helical geometry. Proc. Natl. Acad. Sci. 74(1):221-225

92. Flores H, Lobaton E, Mendez-Diez S, Tlupova S, Cortez R (2005) A study of bacterial flagellar bundling. Bull. Math. Biol. 67(1): $137-168$

93. Elfring GJ, Lauga E (2009) Hydrodynamic phase locking of swimming microorganisms. Phys. Rev. Lett. 103(8):088101

94. Reigh SY, Winkler RG, Gompper G (2012) Synchronization and bundling of anchored bacterial flagella. Soft Matter 8(16):43634372

95. Powers TR (2002) Role of body rotation in bacterial flagellar bundling. Phys. Rev. E 65(4):040903

96. Larsen SH, Reader RW, Kort EN, Tso WW, Adler J (1974) Change in direction of flagellar rotation is the basis of the chemotactic response in Escherichia coli. Nature 249(452):74-77

97. Taylor BL, Koshland D (1974) Reversal of flagellar rotation in monotrichous and peritrichous bacteria: generation of changes in direction. J. Bacteriol. 119(2):640-642

98. Turner L, Ryu WS, Berg HC (2000) Real-time imaging of fluorescent flagellar filaments. J. Bacteriol. 182(10):2793-2801

99. Codling EA, Plank MJ, Benhamou S (2008) Random walk models in biology. J. R. Soc. Interface 5(25):813-834

100. Vladimirov N, Lebiedz D, Sourjik V (2010) Predicted auxiliary navigation mechanism of peritrichously flagellated chemotactic bacteria. PLoS Comput. Biol 6(3):e1000717

101. Saragosti J, Calvez V, Bournaveas N, Perthame B, Buguin A, Silberzan P (2011) Directional persistence of chemotactic bacteria in a traveling concentration wave. Proc. Natl. Acad. Sci. 108(39): $16235-16240$

102. Sourjik V, Wingreen NS (2012) Responding to chemical gradients: bacterial chemotaxis. Curr. Opin. Cell Biol. 24(2):262-268

103. Spagnolie SE, Lauga E (2011) Comparative hydrodynamics of bacterial polymorphism. Phys. Rev. Lett. 106(5):058103

104. Kitao A, Yonekura K, Maki-Yonekura S, Samatey FA, Imada K, Namba K, Go N (2006) Switch interactions control energy frustration and multiple flagellar filament structures. Proc. Natl. Acad. Sci. 103(13):4894-4899

105. Darnton NC, Turner L, Rojevsky S, Berg HC (2007) On torque and tumbling in swimming. Escherichia coli. J. Bacteriol. 189(5): 1756-1764
106. Xie L, Altindal T, Chattopadhyay S, Wu XL (2011) Bacterial flagellum as a propeller and as a rudder for efficient chemotaxis. Proc. Natl. Acad. Sci. 108(6):2246-2251

107. Magariyama Y, Sugiyama S, Muramoto K, Maekawa Y, Kawagishi I, Imae Y, Kudo S (1994) Very fast flagellar rotation. Nature 371(6500):752

108. Asai Y, Kojima S, Kato H, Nishioka N, Kawagishi I, Homma M (1997) Putative channel components for the fast-rotating sodiumdriven flagellar motor of a marine bacterium. J. Bacteriol. 179(16): 5104-5110

109. Magariyama Y, Ichiba M, Nakata K, Baba K, Ohtani T, Kudo S, Goto T (2005) Difference in bacterial motion between forward and backward swimming caused by the wall effect. Biophys. J. 88(5): 3648-3658

110. Goto T, Nakata K, Baba K, Nishimura M, Magariyama Y (2005) A fluid-dynamic interpretation of the asymmetric motion of singly flagellated bacteria swimming close to a boundary. Biophys. J. 89(6):3771-3779

111. Li G, Tam LK, Tang JX (2008) Amplified effect of Brownian motion in bacterial near-surface swimming. Proc. Natl. Acad. Sci. 105(47):18355-18359

112. Altindal T, Xie L, Wu XL (2011) Implications of three-step swimming patterns in bacterial chemotaxis. Biophys. J. 100(1):32-41

113. Stocker R (2011) Reverse and flick: Hybrid locomotion in bacteria. Proc. Natl. Acad. Sci. 108(7):2635-2636

114. Weis RM, Koshland D (1990) Chemotaxis in Escherichia coli proceeds efficiently from different initial tumble frequencies. J. Bacteriol. 172(2):1099-1105

115. Son K, Guasto JS, Stocker R (2013) Bacteria can exploit a flagellar buckling instability to change direction. Nat. Phys. 9(8):494-498

116. Brokaw C (1958) Chemotaxis of bracken spermatozoids implications of electrochemical orientation. J. Exp. Biol. 35(1):197-212

117. Crenshaw HC (1996) A new look at locomotion in microorganisms: rotating and translating. Am. Zool. 36(6):608-618

118. Corkidi G, Taboada B, Wood C, Guerrero A, Darszon A (2008) Tracking sperm in three-dimensions. Biochem. Biophys. Res. Commun. 373(1):125-129

119. Su TW, Choi I, Feng J, Huang K, McLeod E, Ozcan A (2013) Sperm trajectories form chiral ribbons. Sci. Rep. 3:1664

120. Thar R, Fenchel T (2001) True chemotaxis in oxygen gradients of the sulfur-oxidizing bacterium Thiovulum majus. Appl. Environ. Microbiol. 67(7):3299-3303

121. Fenchel T, Blackburn N (1999) Motile chemosensory behaviour of phagotrophic protists: mechanisms for and efficiency in congregating at food patches. Protist 150(3):325-336

122. Boakes DE, Codling EA, Thorn GJ, Steinke M (2011) Analysis and modelling of swimming behaviour in Oxyrrhis marina. J. Plankton Res. 33(4):641-649

123. Machemer H, Sugino K (1989) Electrophysiological control of ciliary beating: a basis of motile behavior in ciliated protozoa. Comp. Biochem. Physiol. A 94(2):365-374

124. Ooya M, Mogami Y, Izumikurotani A, Baba SA (1992) Gravityinduced changes in propulsion of Paramecium caudatum: a possible role of gravireception in protozoan behaviour. J. Exp. Biol. 163:153-167

125. Crenshaw HC (1989) Kinematics of helical motion of microorganisms capable of motion with four degrees of freedom. Biophys. J. 56(5):1029-1035

126. Hyon Y, Powers TR, Stocker R, Fu HC (2012) The wiggling trajectories of bacteria. J. Fluid Mech. 705:58-76

127. Crenshaw HC (1993) Orientation by helical motion - I. kinematics of the helical motion of organisms with up to six degrees of freedom. Bull. Math. Biol. 55(1):197-212

128. Crenshaw HC, Edelstein-Keshet L (1993) Orientation by helical motion - II. changing the direction of the axis of motion. Bull. Math. Biol. 55(1):213-230 
129. Crenshaw HC (1993) Orientation by helical motion - III. microorganisms can orient to stimuli by changing the direction of their rotational velocity. Bull. Math. Biol. 55(1):231-255

130. Machemer H (1989) Cellular behaviour modulated by ions: electrophysiological implications. J. Eukaryotic Microbiol. 36(5): 463-487

131. Ruffer U, Nultsch W (1987) Comparison of the beating of cis-and trans-flagella of Chlamydomonas cells held on micropipettes. Cell Motil. Cytoskeleton 7(1):87-93

132. Ruffer U, Nultsch W (1991) Flagellar photoresponses of Chlamydomonas cells held on micropipettes: II. change in flagellar beat pattern. Cell Motil. Cytoskeleton 18(4):269-278

133. Friedrich BM, Julicher F (2007) Chemotaxis of sperm cells. Proc. Natl. Acad. Sci. 104(33):13256-13261

134. Armitage J, Macnab R (1987) Unidirectional, intermittent rotation of the flagellum of Rhodobacter sphaeroides. J. Bacteriol. 169(2): 514-518

135. Packer HL, Lawther H, Armitage JP (1997) The Rhodobacter sphaeroides flagellar motor is a variable-speed rotor. FEBS Lett. 409(1):37-40

136. Shah DS, Perehinec T, Stevens SM, Aizawa SI, Sockett RE (2000) The flagellar filament of Rhodobacter sphaeroides: $\mathrm{pH}$-induced polymorphic transitions and analysis of the fliC gene. J. Bacteriol. 182(18):5218-5224

137. Armitage JP, Pitta TP, Vigeant MAS, Packer HL, Ford RM (1999) Transformations in flagellar structure of Rhodobacter sphaeroides and possible relationship to changes in swimming speed. J. Bacteriol. 181(16):4825-4833

138. Armitage JP, Schmitt R (1997) Bacterial chemotaxis: Rhodobacter sphaeroides and Sinorhizobium meliloti-variations on a theme. Microbiology 143(Pt 12):3671-3682

139. Porter SL, Wadhams GH, Armitage JP (2008) Rhodobacter sphaeroides: complexity in chemotactic signalling. Trends Microbiol. 16(6):251-260

140. Harrison DM, Packer HL, Armitage JP (1994) Swimming speed and chemokinetic response of Rhodobacter sphaeroides investigated by natural manipulation of the membrane potential. FEBS Lett. 348(1):37-40

141. Attmannspacher U, Scharf B, Schmitt R (2005) Control of speed modulation (chemokinesis) in the unidirectional rotary motor of Sinorhizobium meliloti. Mol. Microbiol. 56(3):708-718

142. Bahlawane C, McIntosh M, Krol E, Becker A (2008) Sinorhizobium meliloti regulator mucR couples exopolysaccharide synthesis and motility. Mol. Plant-Microbe Interact. 21(11):1498-1509

143. Krupski G, Gotz R, Ober K, Pleier E, Schmitt R (1985) Structure of complex flagellar filaments in Rhizobium meliloti. J. Bacteriol. 162(1):361-366

144. Gotz R, Schmitt R (1987) Rhizobium meliloti swims by unidirectional, intermittent rotation of right-handed flagellar helices. J. Bacteriol. 169(7):3146-3150

145. Aizawa SI, Harwood CS, Kadner RJ (2000) Signaling components in bacterial locomotion and sensory reception. J. Bacteriol. 182(6):1459-1471

146. Mitchell JG, Kogure K (2006) Bacterial motility: links to the environment and a driving force for microbial physics. FEMS Microbiol. Ecol. 55(1):3-16

147. Trachtenberg S, Fishelov D, Ben-Artzi M (2003) Bacterial flagellar microhydrodynamics: laminar flow over complex flagellar filaments, analog Archimedean screws and cylinders, and its perturbations. Biophys. J. 85(3):1345-1357

148. Scharf B, Schuster-Wolff-Buhring H, Rachel R, Schmitt R (2001) Mutational analysis of the Rhizobium lupini H13-3 and Sinorhizobium meliloti flagellin genes: importance of flagellin A for flagellar filament structure and transcriptional regulation. J. Bacteriol. 183(18):5334-5342
149. Trachtenberg S, DeRosier DJ, Macnab RM (1987) Threedimensional structure of the complex flagellar filament of Rhizobium lupini and its relation to the structure of the plain filament. J. Mol. Biol. 195(3):603-620

150. Cohen-Krausz S, Trachtenberg S (1998) Helical perturbations of the flagellar filament: Rhizobium lupini $\mathrm{H} 13-3$ at $13 \mathrm{~A}^{\circ}$ resolution. J. Struct. Biol. 122(3):267-282

151. Cohen-Krausz S, Trachtenberg S (2003) The structure of the helically perturbed flagellar filament of Pseudomonas rhodos: implications for the absence of the outer domain in other complex flagellins and for the flexibility of the radial spokes. Mol. Microbiol. 48(5):1305-1316

152. Trachtenberg S, Cohen-Krausz S (2006) The archaeabacterial flagellar filament: a bacterial propeller with a pilus-like structure. J. Mol. Microbiol. Biotechnol. 11(3-5):208-220

153. Jahn TL, Lanoman MD, Fonseca JR (1964) The mechanism of locomotion of flagellates. II. function of the mastigonemes of Ochromonas. J. Eukaryotic Microbiol 11(3):291-296

154. Holwill M, Sleigh M (1967) Propulsion by hispid flagella. J. Exp. Biol. 47(2):267-276

155. Bouck GB (1971) The structure, origin, isolation, and composition of the tubular mastigonemes of the Ochromonas flagellum. J. Cell Biol. 50(2):362-384

156. Brennen C (1975) Locomotion of flagellates with mastigonemes. J. Mechanochem. Cell Motil. 3(3):207-217

157. Cahill DM, Cope M, Hardham AR (1996) Thrust reversal by tubular mastigonemes: immunological evidence for a role of mastigonemes in forward motion of zoospores of Phytophthora cinnamomi. Protoplasma 194(1):18-28

158. Namdeo S, Khaderi S, den Toonder J, Onck P (2011) Swimming direction reversal of flagella through ciliary motion of mastigonemes. Biomicrofluidics 5(3):034108

159. Fischer P, Ghosh A (2011) Magnetically actuated propulsion at low reynolds numbers: towards nanoscale control. Nanoscale 3(2):557-563

160. Peyer KE, Zhang L, Nelson BJ (2013) Bio-inspired magnetic swimming microrobots for biomedical applications. Nanoscale 5(4):1259-1272

161. Ceylan H, Giltinan J, Kozielskia K, Sitti M (2017) Mobile microrobots for bioengineering applications. Lab Chip 17(10): $1705-1724$

162. Chen XZ, Hoop M, Mushtaq F, Siringil E, Hu C, Nelson BJ, Pané $\mathrm{S}$ (2017) Recent developments in magnetically driven micro- and nanorobots. Appl. Mater. Today 9:37-48

163. Sitti M, Giltinan J, Yim S (2015) Biomedical applications of untethered mobile milli/microrobots. Proc. IEEE 103(2):205-224

164. Palagi S, Fischer P (2018) Bioinspired microrobots. Nat Rev Mater 3:113-124

165. Alapan Y, Yasa O, Yigit B, Yasa IC, Erkoc P, Sitti M (2019) Microrobotics and microorganisms: Biohybrid autonomous cellular robots. Annu. Rev. Control Robot. Auton. Syst. 2:205-230

166. Ghosh A, Fischer P (2009) Controlled propulsion of artificial magnetic nanostructured propellers. Nano Lett. 9(6):2243-2245

167. Zhang L, Abbott JJ, Dong L, Kratochvil BE, Bell D, Nelson BJ (2009) Artificial bacterial flagella: fabrication and magnetic control. Appl. Phys. Lett. 94(6):064107

168. Zhang L, Abbott JJ, Dong L, Peyer KE, Kratochvil BE, Zhang H, Bergeles C, Nelson BJ (2009) Characterizing the swimming properties of artificial bacterial flagella. Nano Lett. 9(10):3663-3667

169. Tottori S, Zhang L, Qiu F, Krawczyk KK, Franco-Obregon A, Nelson BJ (2012) Magnetic helical micromachines: fabrication, controlled swimming, and cargo transport. Adv. Mater. 24(6): 811-816

170. Behkam B, Sitti M (2006) Design methodology for biomimetic propulsion of miniature swimming robots. Trans. ASME: J. Dyn. Syst., Meas. Control 128(1):36-43 
171. Qiu F, Zhang L, Peyer KE, Casarosa M, Franco-Obregon A, Choi H, Nelson BJ (2014) Noncytotoxic artificial bacterial flagella fabricated from biocompatible ORMOCOMP and iron coating. Mater. Chem. B 2:357-362

172. Peyer KE, Siringil E, Zhang L, Nelson BJ (2014) Magnetic polymer composite artificial bacterial flagella. Bioinspir. Biomim. 9(4):046014

173. Lee S, Kim S, Kim S, Kim JY, Moon C, Nelson BJ, Choi H (2018) A capsule-type microrobot with pick-and-drop motion for targeted drug and cell delivery. Adv. Healthcare Mater 7(9):e1700985

174. Pak OS, Gao W, Wang J, Lauga E (2011) High-speed propulsion of flexible nanowire motors: Theory and experiments. Soft Matter 7(18):8169-8181

175. Ye Z, Régnier S, Sitti M (2014) Rotating magnetic miniature swimming robots with multiple flexible flagella. IEEE Trans. Robot. 30(1):3-13

176. Peters C, Hoop M, Pané S, Nelson BJ, Hierold C (2016) Degradable magnetic composites for minimally invasive interventions: Device fabrication, targeted drug delivery, and cytotoxicity tests. Adv. Mater. 28(3):533-538

177. Qiu F, Fujita S, Mhanna R, Zhang L, Simona BR, Nelson BJ (2015) Magnetic helical microswimmers functionalized with lipoplexes for targeted gene delivery. Adv. Funct. Mater. 25(11): 1666-1671

178. Alcântara CCJ, Kim S, Lee S, Jang B, Thakolkaran P, Kim JY, Choi H, Nelson BJ, Pané S (2019) 3D fabrication of fully iron magnetic microrobots. Small 15(16):1805006

179. Yan X, Zhou Q, Vincent M, Deng Y, Yu J, Xu J, Xu T, Tang T, Bian L, Wang YXJ, Kostarelos K, Zhang L (2017) Multifunctional biohybrid magnetite microrobots for imagingguided therapy. Sci. Robot 2(12):eaaq1155

180. Ceylan H, Yasa IC, Yasa O, Tabak AF, Giltinan J, Sitti M (2019) 3D-Printed biodegradable microswimmer for theranostic cargo delivery and release. ACS Nano 13(3):3353-3362

181. Mourran A, Zhang H, Vinokur R, Möller M (2017) Soft microrobots employing nonequilibrium actuation via plasmonic heating. Adv. Mater. 29(2):1604825

182. Dreyfus R, Baudry J, Roper ML, Fermigier M, Stone HA, Bibette J (2005) Microscopic artificial swimmers. Nature 437(7060):862865

183. Khalil ISM, Tabak AF, Klingner A, Sitti M (2016) Magnetic propulsion of robotic sperms at low-Reynolds number. Appl. Phys. Lett. 109(3):033701

184. Guo S, Sawamoto J, Pan Q (2005) A novel type of microrobot for biomedical application. In: Proceedings IEEE/RSJ Int. Conf. Int. Rob. Sys. (IROS), pp 1047-1052

185. Guo S, Pan Q, Khamesee MB (2008) Development of a novel type of microrobot for biomedical application. Microsyst. Technol. 14(3):307-314

186. Kosa G, Shoham M, Zaaroor M (2007) Propulsion method for swimming microrobots. IEEE Trans. Robot. 23(1):137-150

187. Kosa G, Jakab P, Hata N, Jolesz F, Neubach Z, Shoham M, Zaaroor M, Szekely G (2008) Flagellar swimming for medical micro robots: theory, experiments and application. In: Proceedings 2nd IEEE RAS and EMBS International Conference on Biomedical Robotics and Biomechatronics (BioRob), pp 258-263

188. Ahmed D, Baasch T, Jang B, Pane S, Dual J, Nelson BJ (2016) Artificial swimmers propelled by acoustically activated flagella. Nano Lett. 16(8):4968-4974

189. Khalil ISM, Tabak AF, Hamed Y, Mitwally ME, Tawakol M, Klingner A, Sitti M (2018) Swimming back and forth using planar flagellar propulsion at low Reynolds numbers. Adv. Sci. 5(2): 1700461
190. Ghanbari A, Bahrami M (2011) A novel swimming microrobot based on artificial cilia for biomedical applications. J. Int. Rob. Sys. 63(3):399-416

191. Ghanbari A, Bahrami M, Nobari MRH (2011) Methodology for artificial microswimming using magnetic actuation. Phys. Rev. E 83(4 Pt 2):046301

192. Palagi S, Jager EW, Mazzolai B, Beccai L (2013) Propulsion of swimming microrobots inspired by metachronal waves in ciliates: from biology to material specifications. Bioinspir. Biomim. 8(4): 046004

193. Sareh S, Rossiter J, Conn A, Drescher K, Goldstein RE (2013) Swimming like algae: biomimetic soft artificial cilia. J. R. Soc. Interface 10(78):20120666

194. Kim S, Lee S, Lee J, Nelson BJ, Zhang L, Choi H (2016) Fabrication and manipulation of ciliary microrobots with nonreciprocal magnetic actuation. Sci. Rep. 6:30713

195. Erkoc P, Yasa IC, Ceylan H, Yasa O, Alapan Y, Sitti M (2018) Mobile microrobots for active therapeutic delivery. Adv. Therap. 2(1):1800064

196. Jeon S, Kim S, Ha S, Lee S, Kim E, Kim SY, Park SH, Jeon JH, Kim SW, Moon C, Nelson BJ, Kim JY, Yu SW, Choi H (2019) Magnetically actuated microrobots as a platform for stem cell transplantation. Sci. Robot 4(30):eaav4317

197. Nelson BJ, Kaliakatsos IK, Abbott JJ (2010) Microrobots for minimally invasive medicine. Annu. Rev. Biomed. Eng. 12:55-85

198. Kummer MP, Abbott JJ, Kratochvil BE, Borer R, Sengul A, Nelson BJ (2010) Octomag: An electromagnetic system for 5DOF wireless micromanipulation. IEEE Trans. Robot. 26(6): 1006-1017

199. Schuerle S, Erni S, Flink M, Kratochvil BE, Nelson B (2013) Three-dimensional magnetic manipulation of micro-and nanostructures for applications in life sciences. IEEE Trans. Magn. 49(1):321-330

200. Ali J, Cheang UK, Martindale JD, Jabbarzadeh M, Fu HC, Kim MJ (2017) Bacteria-inspired nanorobots with flagellar polymorphic transformations and bundling. Sci. Rep. 7(1):14098

201. Fusco S, Sakar MS, Kennedy S, Peters C, Bottani R, Starsich F, Mao A, Sotiriou GA, Pané S, Pratsinis SE, Mooney D, Nelson BJ (2014) An integrated microrobotic platform for on-demand, targeted therapeutic interventions. Adv. Mater. 26(6):952-957

202. Huang HW, Sakar MS, Petruska AJ, Pané S, Nelson BJ (2016) Soft micromachines with programmable motility and morphology. Nat. Commun. 7(1):12263

203. Fusco S, Huang HW, Peyer KE, Peters C, Häberli M, Ulbers A, Spyrogianni A, Pellicer E, Sort J, Pratsinis SE, Nelson BJ, Sakar MS, Pané S (2015) Shape-switching microrobots for medical applications: the influence of shape in drug delivery and locomotion. ACS Appl. Mater. Interfaces 7(12):6803-6811

204. Wolgemuth CW, Powers TR, Goldstein RE (2000) Twirling and whirling: viscous dynamics of rotating elastic filaments. Phys. Rev. Lett. 84(7):1623-1626

205. Lim S, Peskin CS (2004) Simulations of the whirling instability by the immersed boundary method. SIAM J. Sci. Comput. 25(6): 2066-2083

206. Barbara GM, Mitchell JG (2003) Bacterial tracking of motile algae. FEMS Microbiol. Ecol. 44(1):79-87

207. Theves M, Taktikos J, Zaburdaev V, Stark H, Beta C (2013) A bacterial swimmer with two alternating speeds of propagation. Biophys. J. 105(8):1915-1924

208. Ghanbari A, Chang PH, Nelson BJ, Choi H (2014) Magnetic actuation of a cylindrical microrobot using time-delay-estimation closed-loop control: modeling and experiments. Smart Mater. Struct 23(3):035013

209. Ghanbari A, Chang PH, Nelson BJ, Choi H (2014) Electromagnetic steering of a magnetic cylindrical microrobot 
using optical feedback closed-loop control. Int. J. Optomechatronics 8(2):129-145

210. Diller E, Giltinan J, Lum GZ, Ye Z, Sitti M (2016) Six-degree-offreedom magnetic actuation for wireless microrobotics. Int. J. Rob. Res. 35(1-3):114-128

211. Kim S, Qiu F, Kim S, Ghanbari A, Moon C, Zhang L, Nelson BJ, Choi H (2013) Fabrication and characterization of magnetic microrobots for three-dimensional cell culture and targeted transportation. Adv. Mater. 25(41):5863-5868

212. Tung HW, Peyer KE, Sargent DF, Nelson BJ (2013) Noncontact manipulation using a transversely magnetized rolling robot. Appl. Phys. Lett. 103(11):114101

213. Abbott JJ, Peyer KE, Lagomarsino MC, Zhang L, Dong L, Kaliakatsos IK, Nelson BJ (2009) How should microrobots swim? Int. J. Rob. Res. 28(11):1434-1447

214. Temel FZ, Yesilyurt S (2015) Confined swimming of bio-inspired microrobots in rectangular channels. Bioinspir. Biomim. 10(1): 016015

215. Anscombe N (2010) Direct laser writing. Nat. Photonics 4:22-23

216. Buckmann T, Stenger N, Kadic M, Kaschke J, Frolich A, Kennerknecht T, Eberl C, Thiel M, Wegener M (2012) Tailored 3D mechanical metamaterials made by dip-in direct-laser-writing optical lithography. Adv. Mater. 24(20):2710-2714

217. Tottori S, Nelson BJ (2013) Artificial helical microswimmers with mastigoneme-inspired appendages. Biomicrofluidics 7(6):061101

218. Winet H, Bernstein G, Head J (1984) Observations on the response of human spermatozoa to gravity, boundaries and fluid shear. J. Reprod. Fertil. 70(2):511-523

219. Fauci LJ, McDonald A (1995) Sperm motility in the presence of boundaries. Bull. Math. Biol. 57(5):679-699

220. Woolley D (2003) Motility of spermatozoa at surfaces. Reproduction 126(2):259-270

221. Smith D, Gaffney E, Blake J, Kirkman-Brown J (2009) Human sperm accumulation near surfaces: a simulation study. J. Fluid Mech. 621:289-320

222. Elgeti J, Kaupp UB, Gompper G (2010) Hydrodynamics of sperm cells near surfaces. Biophys. J. 99(4):1018-1026

223. Kaupp UB, Kashikar ND, Weyand I (2008) Mechanisms of sperm chemotaxis. Annu. Rev. Physiol. 70(1):93-117

224. Frymier PD, Ford RM, Berg HC, Cummings PT (1995) Threedimensional tracking of motile bacteria near a solid planar surface. Proc. Natl. Acad. Sci. 92(13):6195-6199

225. Frymier PD, Ford RM (1997) Analysis of bacterial swimming speed approaching a solid-liquid interface. AIChE J. 43(5): 1341-1347

226. Kaya T, Koser H (2012) Direct upstream motility in Escherichia coli. Biophys. J. 102(7):1514-1523

227. Lauga E, DiLuzio WR, Whitesides GM, Stone HA (2006) Swimming in circles: motion of bacteria near solid boundaries. Biophys. J. 90(2):400-412

228. Winet H (1973) Wall drag on free-moving ciliated micro-organisms. J. Exp. Biol. 59(3):753-766

229. Jana S, Um SH, Jung S (2012) Paramecium swimming in capillary tube. Phys. Fluids 24(4):041901

230. Li GJ, Ardekani AM (2014) Hydrodynamic interaction of swimmers near a wall. Phys. Rev. E 90(1):013010
231. Zhu L, Lauga E, Brandt L (2012) Self-propulsion in viscoelastic fluids: Pushers vs. pullers. Phys. Fluids 24(5):051902

232. Pak OS, Lauga E (2016) Chapter 4: Theoretical models of lowReynolds-number locomotion in fluid-structure interactions in low-Reynolds-number flows. The Royal Society of Chemistry: 100-167

233. Chwang A, Wu T (1971) A note on the helical movement of micro-organisms. Proc. R. Soc. London, Ser. B 178(1052):327346

234. Li J, de Ávila BE, Gao W, Zhang L, Wang J (2017) Micro/ nanorobots for biomedicine: Delivery, surgery, sensing, and detoxification. Sci. Robot 2(4):eaam6431

235. Hu C, Pané S, Nelson BJ (2018) Soft micro- and nanorobotics. Annu. Rev. Control Robot. Auton. Syst 1:53-75

236. Sánchez MM, Magdanz V, Guix M, Fomin VM, Schmidt OG (2018) Swimming microrobots: Soft, reconfigurable, and smart. Adv. Funct. Mater. 28(25):1707228

237. Palagi S, Singh DP, Fischer P (2019) Light-controlled micromotors and soft microrobots. Adv. Optical Mater 7(16): 1900370

238. Gauvin R, Chen YC, Lee JW, Soman P, Zorlutuna P, Nichol JW, Bae H, Chen S, Khademhosseini A (2012) Microfabrication of complex porous tissue engineering scaffolds using 3D projection stereolithography. Biomaterials 33(15):3824-3834

239. Shin SR, Migliori B, Miccoli B, Li YC, Mostafalu P, Seo J, Mandla S, Enrico A, Antona S, Sabarish R, Zheng T, Pirrami L, Zhang K, Zhang YS, Wan KT, Demarchi D, Dokmeci MR, Khademhosseini A (2018) Electrically driven microengineered bioinspired soft robots. Adv. Mater. 30(10): 1704189

240. Lindemann CB, Lesich KA (2010) Flagellar and ciliary beating: the proven and the possible. J. Cell Sci. 123(Pt 4):519-528

241. Bell DJ, Leutenegger S, Hammar KM, Dong LX, Nelson BJ (2007) Flagella-like propulsion for microrobots using a nanocoil and a rotating electromagnetic field. In: Proceedings (2007) IEEE International Conference on Robotics and Automation, pp 11281133

242. Zeeshan MA, Grisch R, Pellicer E, Sivaraman KM, Peyer KE, Sort J, Özkale B, Sakar MS, Nelson BJ, Pané S (2014) Hybrid helical magnetic microrobots obtained by $3 \mathrm{D}$ template-assisted electrodeposition. Small 10(7):1284-1288

243. Li J, Sattayasamitsathit S, Dong R, Gao W, Tam R, Feng X, Ai S, Wang J (2014) Template electrosynthesis of tailored-made helical nanoswimmers. Nanoscale 6(16):9415-9420

244. Palagi S, Mark AG, Reigh SY, Melde K, Qiu T, Zeng H, Parmeggiani C, Martella D, Sanchez-Castillo A, Kapernaum N, Giesselmann F, Wiersma DS, Lauga E, Fischer P (2016) Structured light enables biomimetic swimming and versatile locomotion of photoresponsive soft microrobots. Nat. Mater. 15(6): 647-653

245. Park J, Jin C, Lee S, Kim JY, Choi H (2019) Magnetically actuated degradable microrobots for actively controlled drug release and hyperthermia therapy. Adv. Healthcare Mater 8(16):1900213

Publisher's note Springer Nature remains neutral with regard to jurisdictional claims in published maps and institutional affiliations. 